\title{
Les gènes de la spermatogènese et leur régulation
}

\author{
V. DROUINEAUD, C. JIMENEZ
}

\begin{abstract}
Laboratoire de Biologie de la Reproduction. Maternité du Bocage. CHU de DIJON 10, boulevard du Maréchal de Lattre de Tassigny. 21000 DIJON
\end{abstract}

\section{RÉSUMÉ}

La production de spermatozoïdes résulte d'un processus complexe et coordonné de division et de différenciation cellulaires appelé spermatogenèse. Chacune des étapes de ce processus, mitose, méiose et spermiogenèse est sous le contrôle de gènes exprimés de manière différentielle dans le testicule.

Le système c-kit/SCF régule la prolifération des spermatogonies tandis que l'équilibre entre l'expression des gènes pro- et anti-apoptotiques permet d'en limiter le nombre.

La méiose est sous le contrôle de plusieurs familles de gènes : 1) les gènes des protéines structurales nucléaires [lamines, histones, protéines du complexe synaptonémal] ; 2) les gènes codant pour les enzymes du métabolisme énergétique [PGK, HK, PGAM ...] ; 3) les gènes codant pour les protéines de réparation de l'ADN et de la recombinaison méiotique ;4) les gènes du cycle cellulaire (gènes suppresseurs de tumeur, gènes du complexe cycline/CDC2, protéine HSP 70-2); 5) les gènes ckit/SCF.

Enfin, le remodelage chromatinien survenant durant la spermiogenèse et reflétant la transformation d'un noyau actif sur le plan transcriptionnel en noyau spermatique quiescent, nécessite une expression séquentielle contrôlée des protéines basiques de liaison à l'ADN : dans les spermatides les protéines histones et non histones sont remplacées par les protéines de transition qui à leur tour sont remplacées par les protamines dans les spermatides en voie d'allongement.

Parmi les gènes exprimés au cours de la spermatogenèse, on distingue : les gènes exprimés exclusivement au cours de la spermatogenèse ;

les gènes codant pour une isoenzyme ou un isotype spécifiquement testiculaire de protéines s'exprimant dans les cellules somatiques (enzymes du métabolisme énergétique)

Les gènes exprimés au cours de la spermatogenèse, spécifiques ou non, subissent une régulation transcriptionnelle et/ou traductionnelle.

La régulation transcriptionnelle des gènes est essentiellement assurée par des facteurs de transcription qui peuvent être spécifiques des cellules germinales ou généraux mais exprimés de manière differentielle dans les cellules germinales. Les gènes des facteurs de transcription sont eux-mêmes soumis à une régulation particulière. Certains gènes exprimés dans le testicule résultent de l'utilisation d'un promoteur alternatif.

La régulation post-transcriptionnelle peutêtre assurée par un épissage alternatif des ARN ou l'arrêt au niveau d'un site de polyadénylation variable.

Des séquences régulatrices des régions 5' et 3' UTR contrôlent la traduction des gènes. La longueur de la queue poly-A et certaines protéines se liant au niveau des régions 3 ' et 5 ' jouent un rôle majeur dans la régulation traductionnelle des gènes.

Mots-clés : spermatogenèse, gène, régulation, transcription, traduction, apoptose. 


\section{INTRODUCTION}

La production de spermatozoïdes résulte d'un processus complexe et coordonné de division et de différenciation cellulaire appelé spermatogenèse. Cette dernière comprend 3 phases :

la phase proliférative qui correspond à l'autorenouvellement et aux divisions mitotiques des spermatogonies ;

la phase méiotique au cours de laquelle les spermatocytes I, issus de la dernière division spermatogoniale, se divisent en spermatocytes II, qui se divisent à leur tour en spermatides rondes ;

la spermiogenèse qui correspond à la métamorphose des spermatides en spermatozoïdes.

Ce processus de différenciation cellulaire est soumis à une régulation de type endocrine assurée par les hormones de l'axe hypothalamo-hypophysaire. En réponse à la stimulation hormonale, il se produit dans les cellules testiculaires une série d'évènements en cascade induisant des changements métaboliques au niveau cellulaire ainsi qu'une modification de l'expression des gènes.

Différents évènements moléculaires se produisent tout au long de la spermatogenèse, avec une expression génique variée et différente à chacune des étapes du processus. Parmi les gènes exprimés dans le testicule, on distingue :

- les gènes exprimés exclusivement durant la spermatogenèse ;

- les gènes codant pour une isozyme ou un isotype spécifiquement testiculaire de protéines s'exprimant dans les cellules somatiques.

Les gènes exprimés au cours de la spermatogenèse peuvent être soumis à une régulation transcriptionnelle, post-transcriptionnelle ou traductionnelle propre.

La régulation transcriptionnelle peut être assurée par la liaison de facteurs protéiques à des séquences du promoteur, ou par un choix variable du promoteur ou du site de polyadénylation.

La régulation post-transcriptionnelle d'un gène au cours de la spermatogenèse s'effectue essentiellement par épissage alternatif.
La régulation traductionnelle est médiée par les séquences régulatrices des régions 5 ' et 3 ' non codantes des ARNm.

\section{DESCRIPTION DES GENES IMPLIQUES DANS LA SPERMATOGENESE}

\section{Phase de multiplication des spermato- gonies}

\section{a) Multiplication et differenciation des spermatogonies : le système c-kit/SCF (stem cell factor)}

Le système c-kit/SCF a un rôle majeur dans la différenciation des spermatogonies. Le facteur steel ou SCF est un facteur de croissance produit par les cellules de Sertoli [193], qui se lie spécifiquement au récepteur c-kit [212]. SCF est localisé principalement à la base de la cellule de Sertoli à des stades du cycle de l'épithélium séminifêre où ces cellules sont en contact étroit avec les spermatogonies de type A [134]. Or, le récepteur de SCF, le proto-oncogène $c$-kit, est exprimé par les spermatogonies de type A. Deux populations de spermatogonies peuvent être distinguées : l'une indépendante de c-kit correspondant aux spermatogonies souches de réserve; l'autre dépendante de c-kit correspondant aux spermatogonies A de type intermédiaire qui prolifêrent et se différencient [228].

Il a été montré que SCF stimulait l'incorporation de thymidine dans les spermatogonies de rat [172]. De plus, Hakovirta et al. [73] ont montré que l'induction de la synthèse d'ADN dans les tubules séminifères était stade-spécifique. SCF empêcherait également l'apoptose des spermatogonies A et permettrait leur survie [154]. Des études ont montré l'importance du role joué par la forme transmembranaire du SCF. En effet, ce dernier existe sous 2 formes, l'une transmembranaire et l'autre soluble, correspondant au produit de clivage de la première. Chez les rongeurs, au début de la spermatogenèse, la production de la forme soluble de SCF est brutalement remplacée par sa forme transmembranaire $[21,133]$, suggérant le rôle plus important joué par cette dernière dans le processus spermatogénétique. Chez des rats dont la spermatogenèse est altérée suite à un 
traitement par l'hexanedione, les cellules de Sertoli produisent principalement la forme soluble du SCF, alors qu'un traitement par le GnRh, aboutit à une augmentation de la synthèse de SCF transmembranaire et stimule la différenciation des spermatogonies [21].

\section{b) Apoptose}

L'apoptose ou mort cellulaire programmée est un processus indispensable à la morphogenèse au cours du développement embryonnaire puis au maintien de l'homéostasie tissulaire dans l'organisme adulte. Celle-ci résulte d'un équilibre entre la prolifération et la mort cellulaire, l'apoptose permettant l'élimination des cellules en surnombre ou endommagées [52, 211].

L'apoptose est un processus génétiquement contrôlé, assuré par l'induction ou l'inhibition de gènes codant pour des protéines provoquant ou bloquant le processus apoptotique [9, 191]. Le dérèglement $\mathrm{du}$ programme génétique intervient dans la physiopathologie de nombreuses maladies, liées soit à une apoptose massive, soit à une inhibition de l'apoptose [138, 195].

La plupart des cellules sont programmées pour la mort cellulaire en l'absence de signaux de survie émanant de l'environnement. Mais dans certains cas, la mort cellulaire est déclenchée par des stimulis externes variables tels que les radiations ionisantes ou les drogues anti-cancéreuses. En revanche, les évènements clés de l'exécution de l'apoptose sont assez similaires quel que soit le type d'induction [161, 191]. L'apoptose est un processus très conservé dans l'évolution [200] et fait intervenir plusieurs types de molécules : des molécules effectrices, inhibitrices et activatrices [191, 32].

Plusieurs étapes sont nécessaires à l'achèvement du processus apoptotique et font intervenir :

- des récepteurs membranaires à domaine de mort cellulaire et leurs ligands (on dit d'un récepteur qu'il est à domaine de mort cellulaire parce qu'il possède au niveau de sa région intra-cytoplasmique carboxy-terminale une séquence capable d'interagir avec les domaines correspondants de protéines intra-cellulaires adaptatrices, qui à leur tour activent les caspases et provoquent la mort cellulaire par apoptose).

- des molécules adaptatrices

- des molécules effectrices : les caspases

- des molécules régulatrices (protéines des la famille Bcl-2 et Apaf-1)

L'apoptose ou mort cellulaire programmée est étroitement contrôlée par l'induction ou l'inhibition des gènes codant pour des protéines proou anti-apoptotiques [9, 191]. Dans la majorité des cas, le processus apoptotique implique la libération par la mitochondrie de molécules pro-apoptotiques telles que le cytochrome $\mathrm{c}$ et l'AIF (Apoptosis Inducing Factor). Des protéines de la famille $\mathrm{Bcl}-2$, ancrées dans la membrane externe de la mitochondrie, déclenchent l'ouverture des pores mitochondriaux et la libération de telles molécules $[94,126,189]$. Dans le cytosol, le cytochrome c, en présence d'ATP et de la protéine APAF-1, active la caspase 9 qui à son tour active des caspases activatrices telles que la caspase 3 , élément central du processus apoptotique dans de nombreux systèmes cellulaires [189].

L'une des voies d'induction de l'apoptose implique le système Fas/Fas L (CD95/CD95 L). Lorsque Fas L se fixe sur son récepteur, celuici se trimérise et son domaine de mort cellulaire s'associe au domaine homologue de la molécule adaptatrice FADD (Fas associated protein with a death domain). Cette dernière présente un domaine effecteur de mort (DED) qui peut activer la voie des caspases [151, 189].

La mort cellulaire se produit également au cours du développement des cellules germinales mâles et semble jouer un rôle majeur au cours de la spermatogenèse $[3,15]$.

A partir de la population initiale de spermatogonies A1, seuls $25 \%$ de spermatocytes préleptotènes sont formés. De même, environ $20 \%$ des cellules germinales meurent par apoptose entre les spermatocytes I et les spermatides matures. Il semble que l'apoptose des cellules germinales dans le testicule soit sous le contrôle de la FSH et de la testostérone $[3,15,19,84$, 96].

Il n'existe pas de mécanisme régulateur permettant d'assurer une densité constante des spermatogonies souches et différenciées le long 
de l'épithélium séminifêre. Un nombre très variable de spermatogonies différenciées est donc produit aux différents endroits le long tube séminifère mais la densité de spermatocytes I est peu variable d'un site à un autre. Une densité optimale et identique en n'importe quel point du tube séminifère est obtenue en augmentant les phénomènes d'apoptose des spermatogonies différenciées dans les sites où ces cellules sont trop nombreuses et en les supprimant dans les sites où elles sont rares.

\section{FAS/Fas Ligand (FAS/Fas L)}

Il a été montré récemment chez la souris, le rat [117] et chez l'homme in vitro que le système Fas/Fas Ligand est impliqué dans la régulation de l'apoptose des cellules germinales.

Chez les rongeurs, Fas Ligand a été localisé par immunohistochimie sur les cellules de Sertoli alors que Fas est présent sur les cellules germinales, surtout les spermatocytes [117]. Une exposition aux rayons X, qui provoque la mort des cellules germinales sans atteindre les cellules de Sertoli [75], entraîne une surexpression de Fas mais pas de Fas Ligand. En revanche, l'administration de produits toxiques pour les cellules de Sertoli (mono-(2 éthylhexyl) phtalate et 2,5-hexanedione) responsables de la destruction secondaire des cellules germinales, entraîne une surexpression de Fas et de Fas Ligand. Les cellules de Sertoli dysfonctionnelles surexprimeraient Fas Ligand afin d'éliminer les cellules germinales Fas +, qui ne peuvent plus être soutenues de façon adéquate.

Ces données permettent de suggérer un modèle de fonctionnement du système Fas/Fas Ligand dans le testicule :

- à l'état normal : les cellules de Sertoli expriment faiblement Fas Ligand, déclenchant l'apoptose de quelques cellules germinales Fas + ;

- en cas d'atteinte des cellules de Sertoli, la capacité de soutien des cellules de Sertoli est diminuée et les cellules germinales ne peuvent plus être soutenues de façon adéquate. Les cellules de Sertoli dysfonctionnelles vont alors surexprimer Fas Ligand pour faciliter l'élimination des cellules germinales Fas + .

Il a été montré que la survie des cellules ger- minales de souris in vitro augmentait après blocage de Fas Ligand avec un oligonucléotide anti-sens [117].

Chez l'homme, la protéine Fas est présente sur les spermatocytes et les spermatides [155]. L'utilisation d'un anticorps antagoniste de Fas Ligand bloque le processus apoptotique induit in vitro par incubation de tubes séminifères dans un milieu de culture sans facteurs de survie [155].

De plus, l'utilisation d'un inhibiteur des caspases, le benzyloxycarbonyl-Val-Ala-Asp (Ome) fluorométhylkétone, inhibe la mort des cellules germinales, suggérant que l'apoptose des cellules germinales induite par Fas est médiée par la voie des caspases [155].

Dans le testicule, le système Fas/Fas L est impliqué dans le maintien de la nature immunologique particulière de cet organe. Les cellules de Sertoli qui expriment Fas L éliminent les lymphocytes T activés qui sont Fas + protégeant ainsi les cellules germinales du système immunitaire et prévenant les réactions de rejet de l'environnement testiculaire.

\section{LA PROTÉINE DEFT (DEATH EFFEcTOR DOMAIN-CONTAINING TESTICULAR MOLECULE)}

Récemment, Leo et al. [120] ont identifié les ADNc codant pour une nouvelle protéine testiculaire : DEFT. L'extrémité N-terminale de celle-ci présente une forte homologie avec les domaines de mort cellulaire des molécules FADD (molécules adaptatrices) et des pro-caspases-8 et -10 (éxécutrices de l'apoptose). Des expériences de Northern Blot effectuées chez l'homme et le rat ont montré que l'expression des ARNm de DEFT était particulièrement importante dans le testicule. Le transcrit de DEFT a été mis en évidence dans les cellules germinales, surtout les spermatocytes [120]. D'autre part, l'expression de DEFT augmente après induction de l'apoptose par un traitement par des antagonistes du GnRH. Du fait de sa forte expression dans les cellules germinales mâles et de son augmentation après induction de l'apoptose, DEFT semble importante dans la régulation de l'apoptose des cellules germinales mâles.

\section{LA FAMILLE BCL-2}

La famille Bcl-2 joue un rôle crucial dans la 
détermination d'une spermatogonie à poursuivre la spermatogenèse ou à évoluer vers l'apoptose. Les protéines de cette famille sont constituées de domaines ( $\mathrm{BH} 1$ et $\mathrm{BH} 2)$ permettant la formation d'homo- ou d'hétérodimères dont la proportion influence l'avenir de la cellule (apoptose ou non). Bcl-2 n'est pas exprimée dans les spermatogonies [108, 169]. Cependant, la surexpression de $\mathrm{Bcl}-2$ a des effets délétères sur la spermatogenèse et est responsable d'une accumulation importante de spermatogonies [58, 169]. Chez la souris transgénique qui surexprime $\mathrm{Bcl} 2$, l'apoptose ne se produit pas.

En fait, certains membres de la famille Bcl-2 pourraient réguler la phase mitotique de la spermatogenèse bien que la protéine $\mathrm{Bcl}-2$ ne semble pas elle-même impliquée.

\section{Le gène Bcl-x}

Ce gène code probablement pour un des facteurs régulant la phase proliférative. Au moins 2 variants de $\mathrm{Bcl}-\mathrm{x}$ sont exprimés dans le testicule : Bcl-xs et Bcl-xl. Alors que Bcl-xl inhibe les phénomènes d'apoptose, Bcl-xs les stimule. Par exemple chez la souris surexprimant Bcl$\mathrm{xl}$, on observe les mêmes phénomènes que chez la souris surexprimant Bcl-2 [169]. De plus, des études immunohistochimiques ont montré que Bcl-xl et/ou Bcl-xs étaient fortement exprimés dans les spermatogonies humaines [18]. Bcl-xl semble donc important dans la régulation de la densité de cellules germinales.

\section{Le gène Bcl-w}

Bcl-w est une protéine anti-apoptotique exprimée dans les spermatides en voie d'allongement et les cellules de Sertoli. Elle n'est pas détectée dans les spermatogonies [171].

Les souris déficientes en Bcl-w présentent une dégénerescence testiculaire et sont stériles. L'atteinte de la lignée germinale est observée 19 jours après la naissance et il existe un arrêt de la spermatogenèse au cours des derniers stades de la spermiogenèse chez les adultes jeunes.

\section{Le gène Bax}

Ce membre de la famille Bcl-2 est un puissant activateur de l'apoptose. Les souris knock-out pour le gène Bax sont stériles et l'analyse his- tologique de leurs testicules montre, comme dans le cas de la surexpression de Bcl-xl ou Bcl-2, une accumulation de spermatogonies [105]. Donc, Bax semble également jouer un rôle important dans le contrôle de l'apoptose des cellules germinales. C'est probablement l'équilibre entre l'expression et l'action de Bax et de Bcl-xl qui contrôle l'apoptose des spermatogonies.

\section{Le gène Diva}

Cette nouvelle molécule régulatrice a été récemment identifiée et caractérisée [89]. L'analyse de sa séquence a montré qu'il s'agissait d'un membre de la famille Bcl-2 (présence de domaines homologues à Bcl-2 BH1, BH2, $\mathrm{BH} 3$ et BH4 et d'un domaine carboxy-terminal hydrophobe). Les transcrits sont détectés dans plusieurs tissus embryonnaires, mais sont présents uniquement dans l'ovaire et le testicule chez la souris adulte [89]. Diva est une protéine pro-apoptotique. Le domaine $\mathrm{BH} 3$ qui assure l'interaction des membres pro-apoptotiques de la famille Bcl-2 avec ses membres antiapoptotiques est absente chez Diva, empêchant cette dernière de se lier avec Bcl-2, Bcl$\mathrm{xl}$, Bcl-w, Mcl-1, A1/Bfl-1. Diva est capable d'induire l'apoptose en l'absence de domaine BH3. De plus, Diva peut interagir avec Apaf-1, molécule impliquée dans l'activation de la caspase -9 et empêcher la liaison de Bcl-xl avec Apaf-1 [89].

\section{LE GÈNE P53}

. Chez les souris sauvages : le transcrit [182] et la protéine p53 sont présents dans les spermatocytes chez la souris [5] comme chez le rat [188]. Aucune expression n'a été retrouvée dans les spermatogonies [5, 18, 182, 188].

Après une irradiation de 4 grays, la protéine p53 est détectée de manière intense au niveau des spermatogonies, alors qu'elle est absente de ces mêmes cellules à l'état normal. Cette dose est normalement responsable d'une apoptose des spermatogonies différenciées [18]. L'augmentation de l'expression de p53 dans les spermatogonies différenciées semble corrélée au processus apoptotique.

Chez les souris déficientes en p53(p53-/-) : chez ces souris, l'apoptose spontanée est plus 
faible que chez les souris p53+/+ et il y a une augmentation du nombre de cellules germinales tétraploïdes. Il y a également une augmentation des formes anormales chez les souris p53 -/- et celles-ci sont moins fertiles (moins de naissances) [226]. Le testicule de ces souris déficientes contient environ $50 \%$ de spermatogonies A1 de plus que celui de la souris normale [18]. Ceci indique que p53 est impliqué dans la régulation du cycle cellulaire des spermatogonies indifférenciées ou qu'il induit normalement l'apoptose dans certaines de ces cellules. Par contre, le nombre de spermatocytes préleptotènes observé chez les souris déficientes en p53 est identique à celui des souris sauvages [18]. Ceci indique que les mécanismes qui contrôlent la densité cellulaire, au niveau des spermatogonies différenciées fonctionne normalement chez la souris déficiente en p53.

Des études effectuées chez la souris p53 -/ ont montré qu'une voie dépendante de p53 était responsable de la phase initiale de l'apoptose des cellules germinales induite par la chaleur [226].

Après irradiation, les testicules de souris déficientes en p53 présentent un nombre élevé de spermatogonies souches géantes [18] capables de dupliquer leur ADN mais incapables de se diviser. Ces cellules entrent en apoptose de façon retardée. En fait, p53 semble nécessaire à l'élimination rapide par apoptose des spermatogonies indifférenciées endommagées.

En ce qui concerne les spermatogonies différenciées, la perte de p53 a des effets plus prononcés. Les spermatogonies sont moins radiosensibles chez la souris déficiente en p53 que chez la souris sauvage et un grand nombre de spermatogonies différenciées survit et se différencie en spermatocytes pachytènes [18] puis en spermatides [75]. De plus, l'apoptose des spermatogonies différenciées est retardée après irradiation des souris déficientes en p53. P53 semble donc jouer un rôle important dans lélimination des spermatogonies différenciées endommagées.

\section{Meiose}

\section{a) Les protéines structurales du noyau}

\section{LES LAMINES}

Les lamines sont des protéines majeures du squelette nucléaire, formant un réseau de mailles sur la face nucléoplasmique de la membrane interne du noyau [61]. Ces protéines jouent un role important dans le maintien de l'intégrité de l'enveloppe nucléaire et de la structure nucléaire. Dans les cellules somatiques, il existe 4 types majeurs de lamines: A, B1, B2 et C. Des transcrits codant pour des lamines nucléaires spécifiques des cellules germinales ont été retrouvés au niveau des spermatocytes au stade pachytène.

Le transcrit d'une lamine de type A, appelée $\boldsymbol{C 2}$, a été mis en évidence dans les spermatocytes pachytène de souris adulte [59]. La séquence nucléotidique de cette lamine est identique à celle de la lamine $\mathrm{A}$ à l'exception de l'extrémité $\mathrm{N}$-terminale. Cela suggère que l'ARNm codant pour la lamine C2 est produit par épissage différentiel à partir du gène de la lamine de type $\mathrm{A}$ durant la spermatogenèse [59].

\section{Le transcrit et la protéine d'une lamine de} type $B$ spécifique du testicule, la lamine B3, ont été détectés dans les spermatocytes pachytène de souris [60]. Le transcrit correspond à un transcrit alternatif du gène de la lamine B2 produit par épissage differentiel spécifique de la méiose et par polyadénylation alternative. La séquence $\mathrm{N}$-terminale spécifique de la lamine B3 pourrait jouer un rôle dans les modifications et les mouvements nucléaires observés au stade pachytène.

\section{LES HISTONES}

Durant la spermatogenèse, les histones somatiques sont d'abord remplacés par des variants spécifiques du testicule. Les gènes codant pour 3 de ces variants sont exprimés pendant la méiose (TH2B, TH2A, H1t). Un autre histone, H4t, est également exprimé dans les spermatocytes pachytène $[64,214,216]$.

\section{Les variants testiculaires TH2A et TH2B}

Chez le rat, les gènes de ces variants ont la même organisation structurale que les gènes somatiques correspondants. L'expression des gènes TH2B et TH2A est corrélée à une hypométhylation de l'ADN : les sites $\mathrm{CpG}$ situés dans la région promotrice de ces gènes sont méthylés dans les cellules somatiques mais non méthylés pendant la spermatogenèse [34, 
35]. Les transcrits de ces 2 variants [87, 101] et leurs protéines [135] ont été détectés pendant la prophase méiotique chez le rat. TH2A et TH2B participent à la formation du nucléosome [33, 162]. Le remplacement de l'histone somatique $\mathrm{H} 2 \mathrm{~B}$ par $\mathrm{TH} 2 \mathrm{~B}$ permettrait la structure relachée de la chromatine dans les spermatocytes pachytènes, rendant possible le processus de recombinaison $[163,164]$.

\section{L'histone H1t}

L'histone H1t se lie à l'ADN de liaison des nucléosomes, influence la structure de la chromatine et agit comme un répresseur transcriptionnel [215]. Les transcrits du gène H1t sont présents dans les spermatocytes du milieu à la fin du stade pachytènes chez le rat $[65,110$, 135]. La protéine H1t a été détectée dans les spermatocytes pachytène et les spermatides rondes de souris [45] et localisée au niveau des chromosomes après le synapsis et l'assemblage des complexes synaptonémaux [139]. En comparaison des autres histones H1, H1t possède moins de motifs de liaison à l'ADN et assure une plus faible condensation de la chromatine [100]. H1t aurait donc un rôle dans la structure de la chromatine des cellules germinales du stade pachytène tardif des spermatocytes jusqu'au début de la condensation chromatinienne dans les spermatides.

\section{La protéine NASP (Nuclear Autoantigenic Sperm Protein)}

Cette protéine nucléaire spécifique des cellules germinales correspondrait à une protéine de liaison aux histones. La protéine NASP a été mise en évidence dans le noyau des spermatocytes leptotène et zygotène, dans le cytoplasme des spermatocytes pachytène et dans le noyau des spermatides [210]. La protéine NASP pourrait être impliquée dans la transition des histones qui survient pendant le remodelage chromatinien méiotique et postméiotique.

\section{Protéines du Complexe synaptonémal}

L'appariement des chromosomes pendant la prophase I se produit parallèlement à l'assemblage du complexe synaptonémal. Les 2 éléments longitudinaux du complexe synaptonémal sont connectés par des filaments transverses. Le complexe synaptonémal constitue le substrat structural sur lequel se produisent les crossing-over et les recombinaisons.

La protéine $\mathrm{SCP1}$ est un composant majeur des filaments transverses dans les spermatocytes de rat et de souris [179, 125]. Elle contient des motifs de liaison à l'ADN et des sites cibles pour la phosphokinase CDC2 [137]. La trancription de SCP1 se produit du stade zygotène au stade diplotène chez le rat [137].

La protéine COR1, codée par un gène exprimé seulement pendant la méiose, a été détectée aux stades leptotène et zygotène de la prophase méiotique I. Elle est localisée sur les chromosomes non appariés avant le synapsis, au niveau des domaines latéraux du complexe synaptonémal après le synapsis, sur les chromosomes après la disjonction [43].

La protéine SC65 a été localisée sur la face interne de l'élément latéral du complexe synaptonémal [30]. Deux transcrits de $2 \mathrm{~kb}$ et $2,4 \mathrm{~kb}$ ont été détectés dans le testicule, le cerveau, le rein et le foie.

La protéine XMR est une protéine associée à la paire de chromosomes XY condensés dans les spermatocytes pachytène. Le gène Xmr appartient à la famille des gènes Xlr (X-chromosome linked, lymphocyte regulated) [27]. Le transcrit a été mis en évidence par Northern-blot dans le testicule de souris. La protéine apparaît dans les spermatocytes préleptotènes, augmente dans les spermatocytes pachytènes puis diminue dans les spermatocytes diplotènes et n'est plus détectée en métaphase I. La protéine est initialement présente dans le noyau puis se localise dans la vésicule sexuelle au stade zygotène, avec une concentration maximale dans l'axe des chromosomes $\mathrm{X}$ et $\mathrm{Y}$ [27].

La protéine du syndrome de Bloom (BLM) : le gène codant pour cette protéine présente une homologie avec la famille des hélicases RecQ. Le syndrome de Bloom provient d'une mutation du gène BLM ; les hommes sont stériles. Dans les spermatocytes de souris, la protéine apparaît sous forme de foyers discrets le long des complexes synaptonémaux des bivalents autosomaux au stade zygotène tardif de la prophase méiotique [205]. Ensuite, ces foyers se désolidarisent de l'axe autosomal pendant le stade pachytène précoce et ne sont plus mis en 
évidence au milieu du stade pachytène [205]. La protéine BLM est localisée aux mêmes endroits que la protéine A de liaison à l'ADN simple brin, protéine impliquée dans le synapsis au cours de la méiose. Cependant, l'apparition de la protéine BLM le long des complexes synaptonémaux est différée par rapport à celle de la protéine A, suggérant que BLM est nécessaire à un stade tardif de la transformation d'une partie de l'ADN génomique pour l'établissement des interactions entre chromosomes homologues durant la prophase méiotique. Au stade pachytène tardif et au stade diplotène, BLM est plus dispersé dans le nucléoplasme, suggérant une possible implication de BLM dans les évènements préparant à la disjonction des chromosomes homologues au cours de l'anaphase I

\section{b) Les enzymes du métabolisme énergétique}

La production d'énergie est un processus hautement conservé nécessitant la transformation du glucose en pyruvate par les enzymes de la voie de la glycolyse. Il existe dans le testicule des isoformes spécifiques de certaines de ces enzymes (caractéristiques fonctionnelles ou électrophorétiques) [47]. On ignore encore pour la plupart de ces isoformes, si elles résultent d'une expression génique spécifique des cellules germinales ou de modifications post-traductionnelles.

\section{Phosphoglycerate Kinase}

La PGK est codée par 2 gènes, Pgk1 et Pgk2. Pgk1 est localisé sur le chromosome $\mathrm{X}$ et est exprimé dans toutes les cellules somatiques, l'ovocyte et les cellules germinales préméiotiques [127, 198]. Le gène Pgk2 est autosomique. Il code pour une isoenzyme spécifique du testicule et est exprimé spécifiquement dans les cellules germinales méiotiques et post-méiotiques [109, 127, 199]. Le gène Pgk2 résulterait d'un processus de duplication du gène Pgk1 par rétroposition survenu tôt dans l'évolution des mammifêres $[128,129]$. Le gène Pgk2 subit une régulation de type transcriptionnel: tandis que certaines séquences de la région promotrice lient des facteurs de transcription ubiquitaires, d'autres séquences situées $40 \mathrm{pb}$ en amont de l'enhancer (E1/E4) lient des facteurs de transcription tissu-spéci- fiques. Plusieurs zones de liaison régulent l'initiation de la transcription et la suppression d'une de ces activités de liaison dans des expériences de transgenèse diminue mais n'abolit pas l'expression du transgène [232]. Ceci implique que de multiples protéines activatrices interagissent de façon combinée pour favoriser la transcription spécifique du gène Pgk2 dans le testicule

Le transcrit de Pgk2 apparaît dès le début de la méiose et son expression augmente dans les spermatocytes aux stades tardifs et dans les spermatides rondes. Au contraire, l'expression de Pgk1 diminue au niveau des spermatocytes pachytènes $[63,111,127,187]$. La conservation d'un duplicat du gène Pgk exprimé uniquement dans les cellules germinales méiotiques et post-méiotiques est avantageuse car elle fournit une source de PGK compensant la repression de l'expression de Pgk1 liée à l'inactivation du chromosome $\mathrm{X}$ au cours de la spermatogenèse $[127,129]$.

\section{HeXokinase [HK]}

3 transcrits différents de l'hexokinase sont présents dans le testicule de souris (Hk1sa, Hk1sb et Hk1sc) [142]. Chez l'homme comme chez la souris, le transcrit de Hk1sa est présent pendant la méiose alors que celui de $\mathrm{Hk} 1 \mathrm{sb}$ est exprimé après la méiose [142]. $\mathrm{Hk} 1 \mathrm{sa}, \mathrm{Hk} 1 \mathrm{sb}$ et Hk1sc résultent d'un épissage alternatif du gène $\mathrm{Hk} 1$.

\section{Phosphoglycerate mutase (PGAM)}

La PGAM est exprimée de manière différentielle au cours de la méiose. L'isoforme PGAM$B$, spécifique du muscle, a été détectée dans les spermatocytes pachytènes et les spermatides, mais pas aux stades précoces de la spermatogenèse chez la souris [57]. Le gène Pgam2 qui code pour PGAM-B commence à être exprimé lors de l'entrée des cellules germinales en méiose chez le rat [25] sans diminution parallèle de l'expression des transcrits du gène constitutif Pgam1.

\section{LACTATE DESHYDROGÉNASE (LDH)}

La LDH permet de convertir le lactate en pyruvate, qui est utilisé dans le cycle de l'acide citrique. Un des membres de la famille des gènes de la $\mathrm{LDH}$, Ldh3, codant pour la $\mathrm{LDH} \mathrm{C}$, 
est exprimé exclusivement dans les cellules germinales. Le transcrit et la protéine de Ldh3 apparaissent au niveau des spermatocytes préleptotènes, sont présents aux stades leptotène et zygotène. Le taux d'ARNm et le niveau d'activité enzymatique de la $\mathrm{LDH} \mathrm{C}$ sont les plus élevés dans les spermatides rondes $[1,122$, 194]. L'activité de la LDH A et de la LDH B est également présente pendant et après la méiose. L'activité de ces deux enzymes diminue au cours de la méiose alors que celle de la $\mathrm{LDH} \mathrm{C}$ augmente [122].

\section{Pyruvate deshydrogénase (PDH)}

Cette enzyme permet la conversion du pyruvate en acétyl-CoA dans la matrice mitochondriale, étape essentielle de l'oxydation aérobie du glucose. La PDH comprend 5 sous-unités. La sous-unité Ea1 contient un site de liaison à un cofacteur et un site de phosphorylation. Ces sites permettent de réguler l'activité de la $\mathrm{PDH}$. Un gène de la sous-unité Ea1 spécifique du testicule, Pdha2, a été cloné chez l'homme et la souris. Le transcrit de Pdha2 a été retrouvé au niveau des spermatocytes leptotène et zygotène. La protéine est présente en quantité importante dans les spermatocytes pachytènes. Le gène Pdha1 est localisé sur le chromosome X, qui subit une condensation dans les spermatocytes, responsable d'une inactivation de la plupart des gènes liés à l'X [74]. Le gène Pdha2 est situé sur un autosome et se substitue au gène Pdha1 lorsque celui-ci est inactivé au cours de la spermatogenèse [38].

\section{Cytochrome c}

Le cytochrome c assure le transport des électrons dans l'espace mitochondrial intra-membranaire. Le cytochrome ct est exprimé exclusivement dans les cellules germinales [202], contrairement au cytochrome cs qui est exprimé dans les cellules somatiques. L'expression des 2 cytochromes c est régulée au cours de la spermatogenèse. La transcription du cytochrome $\mathrm{Ct}$ débute au stade spermatocyte zygotène pour atteindre un maximum dans les spermatides rondes tandis que la protéine est exprimée de manière exponentielle du stade zygotène au stade pachytène $[86,140]$. Un transcrit particulier du cytochrome cs apparait en prophase I et atteint son niveau maximum d'ex- pression dans les spermatides rondes [140]. Ce transcrit résulte de l'utilisation d'un site alternatif d'initiation de la transcription situé en amont de celui destiné aux ARNm plus courts du cytochrome es [72]. Les 2 cytochromes sont donc présents en début de méiose.

\section{c) Protéines de réparation de l'ADN et de la recombinaison méiotique}

Les protéines de réparation de l'ADN participent aussi aux phénomènes de recombinaison méiotique et sont localisées au niveau des complexes synaptonémaux. La plupart des gènes codant pour ces protéines sont exprimés de façon ubiquitaire, mais certains subissent une régulation particulière dans le testicule. L'augmentation du taux de transcrits et de protéines de ces gènes dans les spermatocytes suggère un rôle important dans le déroulement de la méiose.

Le gène Rad51 : Ce gène est l'homologue murin du gène RecA présent chez $E$. coli et qui joue un rôle essentiel dans l'appariement et l'échange entre brins, la recombinaison et la réparation d'ADN. Le gène est transcrit de façon importante dans le testicule [185, 143]. L'ARNm a été détecté au niveau des spermatogonies et des spermatocytes pachytènes [143] et la protéine a été retrouvée en quantité importante dans les complexes synaptonémaux des spermatocytes pachytènes [70].

L'enzyme de conjugaison à l'ubiquitine $\boldsymbol{U b c 9}$ : Le gène est exprimé de manière ubiquitaire, mais à des taux élevés dans le testicule et le thymus. La protéine est présente avec celle du gène Rad51 au niveau du complexe synaptonémal dans les spermatocytes pachytènes chez la souris et pourrait donc jouer un rôle régulateur au cours de la méiose [107].

Le gène Dm1 est l'homologue chez les mammifêres du gène de la levure " disrupted meiotic cDNA " qui intervient spécifiquement au cours de la recombinaison méiotique [20]. Le transcrit est présent dans le testicule de souris adulte ainsi que dans l'ovaire fotal et est particulièrement abondant dans les spermatocytes. Il y aurait 2 transcrits testiculaires produits par épissage alternatif [71].

L'ADN ligase III joue un rôle dans la répara- 
tion des brins d'ADN, la recombinaison méiotique et l'échange entre chromatides sœurs. Son ARNm est retrouvé en quantité 10 fois plus importante dans le testicule que dans les autres tissus chez la souris, et les spermatocytes pachytènes en expriment le plus [31]. Pour être active l'ADN ligase III doit se complexer à la protéine de réparation de l'ADN XRCC1. Les transcrits de xrcc1 sont faiblement exprimés dans les spermatocytes leptotènes et zygotènes alors qu'ils le sont fortement dans les spermatocytes pachytène et les spermatides rondes chez la souris [206].

L'APEX nucléase (apurinic/apyrimidic endonucléase) est une autre enzyme de réparation de l'ADN. Son ARNm est exprimé à des taux élevés dans le testicule et augmente particulièrement lors de la première vague de spermatogenèse chez le jeune rat au moment où les spermatocytes pachytènes apparaissent et augmentent en nombre. L'expression du transcrit de l'APEX nucléase augmente donc pendant la méiose, suggérant un rôle de cette enzyme dans ce processus.

Le gène Pms2 : L'absence de gène Pms2 provoque une infertilité chez la souris mâle mais pas chez la femelle [12]. Les spermatocytes contiennent des vacuoles et il y a peu de spermatides. Le synapsis et l'organisation du complexe synaptonémal sont perturbés.

Le gène Mlh1 : l'absence de ce gène est responsable d'une stérilité chez les souris mâle et femelle. Le mâle ne produit pas de spermatozoïdes $[13,49]$. Il existe un nombre élevé de chromosomes séparés prématurément et la spermatogenèse est arrêtée au stade pachytène tardif ou en métaphase.

Les gènes ATM : La protéine ATM est localisée le long des chromosomes en synapsis. La mutation du gène ATM chez la souris entraîne une infertilité dans les 2 sexes, avec un arrêt de la méiose au stade zygotène/pachytène [14, $53,222]$. L'ARNm et la protéine du gène Atr (ataxia-telangiectasia-and rad3-related) sont retrouvés aux taux les plus élevés dans les spermatocytes au stade pachytène et la protéine est localisée le long des axes des chromosomes non appariés [99]. Ces protéines auraient un rôle direct dans la reconnaissance et la réparation des brins d'ADN interrompus durant la recombinaison méiotique [99] ;

- La poly (ADP) ribose polymerase (PARP) est une protéine associée à la chromatine qui catalyse la fixation de l'ADP ribose à des protéines nucléaires. L'activité de cette enzyme augmente consécutivement à des lésions de l'ADN, suggérant un rôle dans la réparation de l'ADN [6, 40]. C'est aussi un composant du complexe de réplication de l'ADN [186] et son clivage par les caspases constitue une étape clé dans l'apoptose [149]. Des taux élevés d'ARNm ont été retrouvés dans le testicule [136, 152] avec une expression maximum dans les spermatocytes pachytènes tandis que les taux sont réduits dans la spermatide [2]. La protéine est également localisée dans les spermatocytes pachytènes en quantité importante [36]. Cependant, son absence ne provoque pas d'infertilité chez la souris [207] ;

L'ADN polymerase $\beta$ : le transcrit est présent en quantité importante dans le testicule de rat et de souris [150]. L'expression est faible dans les spermatocytes leptotènes et zygotènes, augmente dans les spermatocytes pachytènes et les spermatides rondes de souris [2]. Il existe une forte activité de cette enzyme dans les cellules méiotiques et post-méiotiques testiculaires [66, 77, 78].

LINE-1 : correspond à de l'ADN répétitif. L'ARNm de LINE-1 est présent en grande quantité dans les spermatocytes leptotènes et zygotènes chez la souris [22]. LINE-1 participerait à la réparation d'ADN [203] et pourrait aussi participer à la génération des rétroposons tels que Pgk2 ou Pdha2 pendant la méiose.

\section{d) Gènes du cycle cellulaire}

\section{LES GÈNES SUPPRESSEURS DE TUMEUR}

Quelques gènes suppresseurs de tumeur sont impliqués dans le cycle cellulaire et sont fortement exprimés pendant la phase méiotique de la spermatogenèse.

p53 : p53 est exprimé de manière importante dans le testicule et la transcription se produit surtout dans les spermatocytes pachytènes. Chez la souris knock-out pour le gène p53, certains spermatocytes n'achèvent pas leur méio- 
se et forment des cellules géantes multinucléées ; néanmoins ces souris sont fertiles [173].

Le gène $\boldsymbol{R b} 1$ : ce gène est fortement exprimé dans le testicule, avec l'apparition d'un court transcrit en fin de méiose [16].

Le gène Brca1 : ce gène est également exprimé de façon importante dans les spermatocytes pachytènes et les spermatides rondes [229]. La protéine est associée aux complexes synaptonémaux en développement, sur les éléments axiaux des chromosomes méiotiques avant le synapsis [183].

\section{COMPLEXE CYCLINE ET CDC2 OU MPF} (Maturation Promoting Factor)

L'entrée en phase $M$ est déclenchée par l'activation d'une protéine kinase appelée MPF. Celle-ci est constituée de 2 sous-unités :

1) une sous-unité catalytique (cdk) : CDC2 ou p34cdc2 ;

2) une sous-unité régulatrice : la cycline. Il existe 8 cyclines différentes et 6 kinases dépendantes des cyclines. Cette entrée en phase $M$ comprend deux étapes :

1) l'activation des cdk (kinases dépendantes des cyclines) par fixation de cyclines spécifiques et phosphorylation au niveau d'un résidu thréonine (thr 161) par une autre protéine kinase (en revanche la phosphorylation des résidus Thr14 et Tyr 15 inhibe l'activité de la cdk). La protéine CDC25 est une phosphatase qui permet d'activer la cdk par élimination des 2 groupements phosphates inhibiteurs présents sur les résidus Thr14 et Tyr15. 2) la phosphorylation de protéines spécifiques par la cdk.

Le transcrit et la protéine de la cycline $\boldsymbol{B} \boldsymbol{1}$ sont retrouvés en quantité élevée dans les spermatocytes pachytènes et les spermatides, alors que l'activité CDC2 kinase dépendante de la cycline B1 est présente dans les spermatocytes pachytènes mais pas dans les spermatides [29].

Les transcrits de la cycline $\boldsymbol{B 2}$ sont détectés à des niveaux élevés dans les spermatocytes pachytènes et diplotènes [28].

L'ARNm de la cycline A1 est présent dans le testicule de souris, plus particulièrement au niveau des spermatocytes pachytènes tardifs. Il n'est pas retrouvé aux stades post-méiotiques.

Les transcrits de la phosphatase CDC25 sont présents en grande quantité dans le testicule. Un transcrit de $1,9 \mathrm{~kb}$, résultant probablement d'un épissage spécifique dans le testicule, est fortement exprimé au niveau des spermatocytes pachytènes et diplotènes et persiste dans les spermatides rondes [219]

Le gène Mak (male germ cell-associated kinase) est un membre de la famille CDC2 et est exprimé dans les spermatocytes pachytènes tardifs [106]. Un autre transcrit est présent dans les spermatides [208].

\section{PRotÉINe HSP70}

\section{HSP70-2}

Les membres de la famille des proteines de choc thermique sont des molécules chaperones intervenant dans le repliement, le transport et l'assemblage d'autres protéines. L'une de ces protéines, HSP70-2, est spécifiquement exprimée pendant la prophase de la première division méiotique des cellules germinales mâles. La transcription de HSP70-2 démarre aux stades leptotène et zygotène de la prophase I pour atteindre un niveau élevé dans les spermatocytes I de stade pachytène $[41,170,230]$. La protéine est retrouvée au niveau des spermatocytes pachytènes en association avec les éléments latéraux du complexe synaptonémal [4].

Les souris mâles homozygotes pour la mutation HSP70-2 \%- sont stériles avec un arrêt de développement des spermatocytes au stade pachytène. Ces derniers entrent en apoptose au moment de la transition G2/M pendant la première division méiotique [42]. Ceci suggère que HSP70-2 est une molécule chaperone des CDK intervenant dans cette phase du cycle cellulaire. Il a été montré que HSP70-2 interagissait avec $\mathrm{CDC} 2$ et constituait une molécule chaperonne pour $\mathrm{CDC} 2$ indispensable à la formation du complexe CDC2/cycline B1 [234].

A l'état normal, l'activité CDC2 kinase est surtout présente dans les spermatocytes pachytènes [29]. Aussi, la dissociation du complexe CDC2/cycline B1 et l'absence d'activité CDC2 
kinase observée chez la souris HSP70-2 -/pourrait expliquer l'arrêt de la spermatogenèse au cours de la phase méiotique.

HSP70-2 est détecté dans les spermatocytes du stade zygotène au stade diplotène au niveau des complexes synaptonémaux suggérant un rôle dans la formation des complexes synaptonémaux et la réparation d'ADN.

\section{HSC70t}

Le gène Hsc70t est un membre de la famille des gènes de la famille Hsp70. Chez la souris, ce gène est exprimé constitutivement après la méiose au cours de la spermatogenèse. Le transcrit apparait au stade 7 et disparait au stade 15 de la spermiogenèse [197]. La protéine est détectée à partir des spermatides de stade 9 jusqu'à l'étape finale de la spermatogenèse chez la souris [197]. Le gène de Hsc70t est transcrit après la méiose, mais la traduction est retardée. $\mathrm{Il}$ existe donc une régulation traductionnelle de cette protéine.

\section{Système c-kit/SCF}

Linteraction de c-kit avec son ligand SCF serait essentielle pour la méiose. Les travaux de Vincent et al. [201] confortent cette hypothèse. Ainsi, chez la souris, aux stades VII-VIII du cycle de l'épithélium séminifêre, c'est à dire au moment où les spermatocytes entrent en méiose, la forme transmembranaire de SCF a été détectée de la partie basale à la partie adluminale des cellules de Sertoli sur certaines sections de tube séminifère. Le récepteur c-kit a été retrouvé à la surface des spermatocytes pachytène. Dans un système de coculture mettant en présence la lignée de cellules de Sertoli différenciées $15 \mathrm{P}-1$ et une suspension cellulaire enrichie en spermatocytes pachytènes, l'addition d'un anticorps monoclonal bloquant dirigé contre c-kit (ACK2) provoque l'absence d'apparition des cellules haploïdes. L'addition de la forme soluble de SCF à la coculture empêche également l'achèvement du processus méiotique, suggérant l'importance de l'interaction entre c-kit et la forme transmembranaire de SCF, déplacée ici par la forme soluble.

Il semble donc, qu'en plus de son rôle régulateur dans la phase proliférative, le système ckit/ligand contribue de manière importante à l'interaction des spermatocytes avec les cellules de Sertoli.

\section{Spermiogenese}

La spermiogenèse est caractérisée par un remodelage majeur de la structure chromatinienne qui ,de diffuse dans le noyau de la spermatide ronde, devient très condensée dans celui de la spermatide allongée et du spermatozoïde. Ces modifications reflètent la transformation d'un noyau actif sur le plan transcriptionnel en noyau spermatique quiescent et nécessitent une expression séquentielle contrôlée des protéines basiques de liaison à l'ADN : dans les spermatides rondes, les protéines histones et non histones sont remplacées par les protéines de transition (TP), qui à leur tour sont remplacées par les protamines $(P)$ dans les spermatides en voie d'allongement. Les protamines constituent les principales protéines nucléaires basiques du spermatozoïde mature.

Chez les mammifères, les gènes des protéines de transition et des protamines sont transcrits dans les spermatides rondes et en élongation. Les ARNm sont alors stockés sous forme de ribonucléoprotéines pendant quelques jours, où leur traduction est réprimée. Ils sont ensuite traduits dans les spermatides en voie d'allongement et dans les spermatides allongées [37, 48, 80, 81, 82, 83, 104, 141]. Cependant des ARNm de TP1 et de P1 et P2 ont été retrouvés dans les spermatozoïdes épididymaires et éjaculés et pourraient correspondre à des ARNm résiduels stockés n'ayant pas été traduits.

Il existe donc une expression séquentielle des nucléoprotéines durant la spermiogenèse. Celle-ci a été mise en évidence chez l'homme notamment (Figure 1):

TP1 : les ARNm de TP1 sont présents du stade 2 au stade 4 des spermatides alors que la protéine n'est synthétisée qu'aux stades 3 et 4 [190, 220, 221]. Le transcrit est exprimé faiblement dans les spermatides de stade 4 ; à l'inverse la protéine est présente à un taux maximal à ce stade [190]. Ces observations suggèrent l'existence d'une régulation à la fois transcriptionnelle et traductionnelle de l'expression de TP1 (voir infra).

TP2 : cette protéine de transition est détectée dans les spermatides de stade 1 à 5 . Le gène est exprimé très faiblement $[190,220,221]$. 


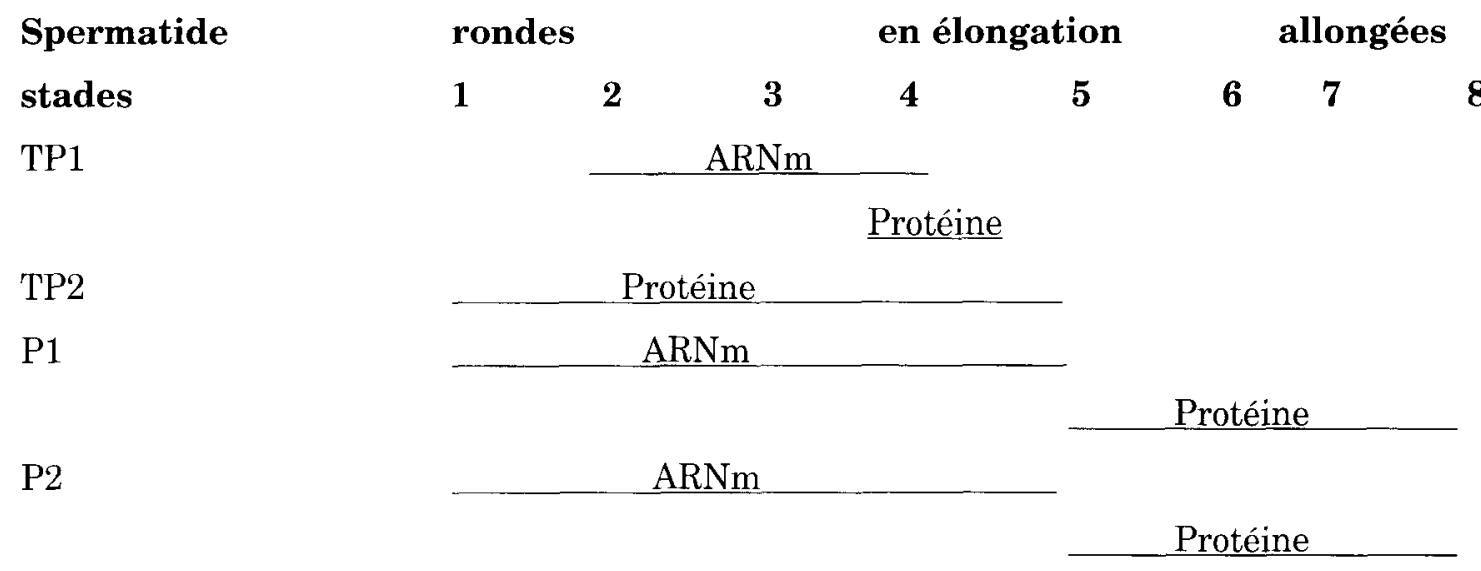

Figure 1 : expression sequentielle des nucléoprotéines au cours de la spermatogenèse humaine.

Ceci pourrait être secondaire à une instabilité avec dégradation rapide des ARNm de TP2.

P1 et P2 : Les ARNm sont exprimés au niveau des spermatides de stade 1 à 4 tandis que la protéine apparaît de façon retardée aux stades 4 à 8 des spermatides [118, 121, 159, 174, 175, $177,220,221]$.

La protamine 1 est synthétisée sous forme mature alors que la protamine 2 est synthétisée sous forme de précurseur [44, 223].

\section{REGULATION DES GENES DE LA SPERMATOGENESE}

Les phénomènes de division et de différenciation caractérisant la spermatogenèse sont régis par une régulation transcriptionnelle et/ou traductionnelle complexe des gènes exprimés au cours de ce processus.

\section{Régulation transcriptionnelle}

Elle est essentiellement assurée par des facteurs de transcription qui peuvent être spécifiques de la lignée germinale ou généraux, mais exprimés de manière différentielle dans les cellules germinales. D'autres éléments interviennent dans la régulation transcriptionnelle des gènes exprimés durant la spermatogenèse : la structure chromatinienne, l'acétylation des histones, la dissociation des gènes avec la matrice nucléaire et l'état de méthylation de l'ADN.

\section{a) Promoteurs et facteurs de transcription}

L'interaction entre des éléments de régulation de l'ADN agissant en cis et des facteurs pro- téiques agissant en trans joue un rôle prédominant dans la régulation de la transcription des gènes dans les cellules eukaryotes. Certains facteurs de transcription sont exprimés spécifiquement au cours de la spermatogenèse et appartiennent à différentes familles incluant les proto-oncogènes, la superfamille des récepteurs nucléaires, les familles GATA, bZIP et des gènes à domaine homéobox. A ces facteurs s'ajoutent la protéine p53 et la TATAbinding protein (TBP) [119].

Les proto-oncogènes : Les membres appartenant à la sous-classe des protéines nucléaires peuvent agir comme facteurs de transcription. C-Fos, c-Jun, c-Myc, A-Myb, B-Myb sont exprimés par les cellules germinales. Fos et Jun peuvent former des homo- ou des hétérodimères.

La famille Myc est formée de 3 protéines cMyc, N-Myc et L-Myc [85]. La famille Myb est composée de 3 membres, A-Myb, B-Myb et CMyb. Ces protéines comportent un domaine hautement conservé de liaison à l'ADN et des domaines moins conservés de transactivation et de régulation négative [95]. Chez la souris, seuls A-Myb et B-Myb sont exprimés dans le testicule [116].

\section{La famille GATA}

Les membres de la famille GATA contiennent un ou deux motifs conservés en doigt de gant se liant à l'ADN. GATA-1 et GATA-4 sont exprimés dans le testicule murin $[10,90]$. GATA- 1 est exprimé dans les cellules de Sertoli, aux stades VII-IX du cycle de l'épithélium séminifêre de souris $[90,227]$. 
La TATA-binding protein (TBP) est nécessaire à l'action des polymérases pour le démarrage de la transcription des gènes. Chez les rongeurs, la TBP est régulée pendant la spermatogenèse [157].

\section{La famille bZIP}

Les membres de cette famille exprimés dans le testicule incluent la protéine de liaison à l'élément de réponse à l'AMPc $\mathrm{CRE}(\mathrm{CREB})$, la protéine modulatrice de CRE (CREM) et leurs isoformes [114, 204]. Ces protéines possèdent un domaine basique de liaison à l'ADN. Dans le testicule, CREB et CREM interviennent dans l'activation FSH-dépendante de l'AMPc à de multiples niveaux.

\section{La superfamille des récepteurs nucléaires}

Cette famille comprend les facteurs activés par les hormones lipophiles, incluant les stéroïdes, les rétinoïdes, les hormones thyroïdiennes et la vitamine $\mathrm{D}$, ainsi que les facteurs dont le ligand n'a pas été identifié (récepteurs orphelins) [130]. Sur le plan structural, ils sont formés d'une région $\mathrm{N}$-terminale, spécifique de chaque récepteur, d'un domaine conservé de liaison à l'ADN et d'un domaine de liaison au ligand. 2 récepteurs sont d'un intérêt particulier au niveau du testicule :

\section{- Les récepteurs des rétinoïdes :}

La vitamine A est indispensable au bon déroulement de la spermatogenèse et son action s'effectue par l'intermédiaire des récepteurs de l'acide rétinoïque (RARs) et des récepteurs des rétinoïdes X (RXRs). Ces récepteurs appartiennent à la superfamille des récepteurs nucléaires et sont capables de se lier à leurs ligands ainsi qu'à l'ADN. Chaque classe est formée de 3 gènes : $\operatorname{RAR} \alpha, \beta$, $\gamma$ et $\operatorname{RXR} \alpha, \beta$, $\gamma$, dont la transcription conduit à la formation de plusieurs isoformes du fait de l'utilisation de promoteurs alternatifs et d'un épissage alternatif [24, 97]. L'acide trans-rétinoïque (ATRA) et l'acide 9-cis-retinoïque (9-cis RA) peuvent se lier aux RARs, mais seul le 9-cis RA est capable de se lier aux RXRs [131]. Il peut se former des récepteurs homodimères ou hétérodimères. Ces dimères peuvent se lier à différents éléments de réponse dans les promoteurs de certains gènes et agir comme des facteurs de transcription [97, 132]. Les RXRs peuvent former des hétérodimères avec les RARs et un certain nombre d'autres membres de la famille des récepteurs des hormones stéroïdes [132]. Ils peuvent aussi former des homodimères qui se lient à des éléments de réponse autres que les hétérodimères [231]

- Les récepteurs nucléaires orphelins dont le facteur nucléaire des cellules germinales [GCNF] qui est exprimé durant la spermiogenèse [88].

\section{Les protéines à homéobox}

Ces facteurs de transcription contiennent un domaine hautement conservé de liaison à l'ADN, le motif homéobox. Les gènes à domaine homéobox sont groupés tels Hox ou dispersés sur le génome (Spx-1, Esx-1, PEM, Sry et Sox). Ces 2 types de gènes sont exprimés au niveau des cellules germinales ou somatiques testiculaires et sont impliqués dans le processus spermatogénétique $[23,181,123,124$, 217]. Cette famille comprend aussi les gènes à domaine POU (Pit, Oct et Unc) qui correspond à un domaine de liaison à l'ADN de 150 à 160 acides aminés. Le rôle des gènes homéobox dans la spermatogenèse n'est pas connu.

Le gène p53 est un gène suppresseur de tumeur qui peut également agir comme facteur de transcription

\section{b) Expression et rôle des facteurs de trans- cription au cours de la spermatogenèse}

\section{Phase mitotique}

Certains gènes à domaine homéobox sont exprimés spécifiquement dans le testicule au cours de cette phase. Il s'agit des gènes $\mathrm{Spx} 1$ et Esx1 qui sont exprimés dans les spermatogonies. Ces gènes sont également exprimés par les spermatocytes préleptotènes et les spermatides rondes $[23,123]$. Ces gènes liés à l'X sont inactivés pendant la prophase méiotique du fait de la formation de la vésicule sexuelle. Leur transcription pourrait être réactivée après la méiose [111]. La protéine d'un gène à domaine POU, Oct 4 est également retrouvée dans les spermatogonies A [158].

. Les proto-oncogènes $\mathrm{c}$-fos, c-jun et c-myc sont exprimés dans les cellules germinales. C-fos est uniquement exprimé par les spermatogonies $\mathrm{B}$ tandis que c-jun et c-myc le sont au 
niveau des spermatogonies $B$ et des spermatocytes préleptotènes [216]. Ces gènes pourraient avoir un rôle important pour l'entrée en méiose. L'absence de gène c-fos chez la souris entraîne une spermatogenèse anormale [92]. Le transcrit B-myb est fortement exprimé dans les spermatogonies, les spermatocytes précoces [116]. Son expression diminue quand les spermatocytes tardifs apparaissent [116]. A-myb est exprimé de façon moins importante que B-myb dans les spermatogonies [116].

\section{Phase méiotique}

- Les proto-oncogènes A-myb et B-myb sont exprimés dans les cellules germinales mitotiques et méiotiques selon un profil différent. Tandis que le transcrit de A-myb est faiblement exprimé dans les spermatogonies et l'est fortement dans les spermatocytes I, un profil d'expression inverse est observé pour B-myb (forte expression dans les spermatogonies et faible expression dans les spermatocytes I tardifs) [116]. Ces données suggèrent un rôle différent pour ces 2 proto-oncogènes : B-myb serait plutôt impliqué dans la phase proliférative et A-myb dans la phase méiotique. Cette hypothèse est confortée par le fait que les souris déficientes en A-myb ont des spermatogonies et des spermatocytes préleptotènes normaux alors que la plupart des spermatocytes I sont dégénérés et qu'aucune spermatide n'est détectée [196].

- Les gènes à domaine homéobox sont également transcrits durant la méiose. Hoxa4 est exprimé fortement dans les cellules germinales mâles méiotiques et post-méiotiques [217]. Hoxb4 est exprimé faiblement dans les cellules somatiques et germinales alors que Hoxd4 est exprimé uniquement dans les cellules de Leydig.

- Les gènes à domaine POU : une protéine à domaine POU, spécifique du testicule, et appelée Sperm-1, a été mise en évidence chez le rat et la souris [8]. Les transcrits de Sperm-1 sont exprimés dans les spermatocytes I aux stades pachytène et diplotène, suggérant un rôle de Sperm-1 dans le processus méiotique.

\section{Spermiogenèse}

- Système CRE / CREM / CREB : (cAMP response element/cAMP response element modula-
tor/cAMP response element binding protein).

La régulation de la spermatogenèse est assurée en partie par les hormones gonadotropes hypophysaires qui agissent en activant la voie de signalisation dépendante de l'AMPc [67, 184]. L'étape finale consiste en une activation de 2 facteurs de transcription nucléaires : CREB et CREM qui se lient aux éléments de réponse à l'AMPc (CRE). Quelques gènes cibles de CREM ont été identifiés, comme les gènes de TP1, TP2, P1, P2, de l'acétylcholine estérase et de la calspermine $[39,102,192,233]$. CREB et CREM en se fixant sur les CRE de ces gènes, modulent l'expression de ces derniers qui en retour permettent l'achèvement de la spermatogenèse.

Deux types d'isoformes sont produites à partir des gènes de CREM et de CREB : des isoformes activatrices et des isoformes inhibitrices de l'expression génique. Ces différentes isoformes sont produites par épissage alternatif, utilisation d'un promoteur différent ou autorégulation des promoteurs (régulation par l'isoforme de son propre promoteur)[115, 204].

En ce qui concerne CREM, seules les formes inhibitrices sont exprimées dans les cellules germinales préméiotiques chez la souris, alors que les formes activatrices sont présentes plus tard. Ces dernières sont exprimées à partir du stade pachytène [55]. Elles s'accumulent dans les spermatocytes de stade pachytène tardif et dans les spermatides rondes après un changement du site de polyadénylation utilisé, qui permet une meilleure stabilité des transcrits [56]. La forme activatrice de la protéine CREM est détectée en grande quantité dans les spermatides rondes chez la souris [55].

Il en est de même dans l'espèce humaine : les transcrits des formes inhibitrices de CREM sont présents dans les cellules préméiotiques et absents dans les cellules post-méiotiques ; les transcrits des formes activatrices sont présents au niveau des spermatides [156].

Les souris mâles déficientes en gène CREM sont stériles avec un arrêt de maturation au stade spermatide ronde et une augmentation du nombre de cellules germinales en apoptose dans les tubes séminifêres [146]. De même, Weinbauer et al. [209] ont mis en évidence l'ab- 
sence de protéine CREM chez des hommes infertiles présentant un arrêt de maturation au stade spermatide. Comme l'ont montré Péri et al. [156], les formes inhibitrices de CREM étant les seuls isoformes retrouvées chez les hommes oligospermiques, les désordres de la spermatogenèse pourraient être consécutifs à l'absence d'expression des formes activatrices de CREM.

Le transcrit de CREB est également exprimé dans le testicule mais à un niveau beaucoup plus faible $[39,55]$. La distribution de la protéine CREB est similaire à celle de la protéine CREM. La fonction de CREB n'est pas encore confirmée dans la physiologie testiculaire. En effet, elle n'apparaît pas indispensable au déroulement de la spermatogenèse, puisque les souris déficientes en gène CREB conservent une spermatogenèse normale.

La protéine kinase $\mathrm{A}(\mathrm{PKA})$ joue un rôle essentiel dans la voie de signalisation AMPc dépendante puisqu'elle phosphoryle et active les facteurs de transcription CREB et CREM. L'activité de la PKA change au cours de la spermatogenèse pour atteindre un maximum dans le spermatozoïde. Il existe un profil d'expression différentielle des ARNm pour 5 sousunités de la PKA dans les cellules germinales [153]. Les transcrits de $\operatorname{Ri} \alpha, \operatorname{Ri} \beta$ et $\mathrm{C} \alpha$, sont présents aux stades préméiotiques alors que ceux de RII $\alpha$ et RII $\beta$ apparaissent dans les cellules haploïdes. Ces derniers s'accumulent dans les cellules où se trouve la protéine CREM.

\section{- Le Germ Cell Nuclear Factor (GCNF)}

Le GCNF est un récepteur nucléaire orphelin qui pourrait également jouer un rôle dans la régulation transcriptionnelle des gènes de la protamine.

Le GCNF est exprimé à partir du stade spermatide ronde [98]. Ce facteur se lie à la séquence répétée AGGTCA, appelée séquence DRO. Ces séquences sont présentes notamment dans les régions promotrices 5' des 2 gènes de la protamine, $\mathrm{P} 1$ et $\mathrm{P} 2$ [88]. En se liant aux séquences DRO des promoteurs des gènes $\mathrm{P} 1$ et $\mathrm{P} 2, \mathrm{GCNF}$ pourrait contribuer à l'expression de ces gènes. La proximité des séquences $\mathrm{DRO}$ avec les éléments de réponse à
l'AMPc [CRE] [39] permettrait l'interaction de GCNF et de CREM. Cette interaction pourrait permettre l'activation intense de l'expression des gènes de la protamine.

\section{- La TATA-Binding Protein (TBP)}

La TBP et ses facteurs associés sont nécessaires à l'initiation de la transcription par les polymerases.

L'expression de la TBP est régulée durant la spermatogenèse. Il existe d'abord une augmentation de la transcription du gène de la TBP, survenant à certains stades de la spermatogenèse et conduisant à l'accumulation de transcrits de la TBP au niveau des spermatocytes pachytènes et des spermatides rondes [157]. Les taux d'ARNm de ce facteur sont 40 fois plus élevés dans le testicule que dans les cellules somatiques [157]. Les ARNm de la TBP testiculaire sont transcrits à partir de promoteurs spécifiques du testicule, en complément des promoteurs des cellules somatiques [180].

Contrairement à l'accumulation des transcrits, les concentrations de la protéine ne sont pas aussi importantes (2,5 fois plus que dans les cellules somatiques) [157]. L'analyse des gradients polysomaux (cette technique consiste à utiliser des gradients de sucrose pour déterminer la quantité d'ARNm associés aux polysomes et engagés dans le processus traductionnel) suggère la possibilité d'une répression traductionnelle des ARNm de la TBP [157].

Il est possible que l'augmentation de la transcription de la TBP pendant la spermatogenèse corresponde à un mécanisme homéostatique spécifique des cellules germinales, visant à compenser la répression traductionnelle et à maintenir des concentrations protéiques de TBP suffisamment élevées pendant le développement spermatogénétique.

\section{c) Choix variable du promoteur}

Des transcrits exprimés spécifiquement au cours de la spermatogenèse peuvent résulter d'un choix différentiel du promoteur lors de la transcription (cytochrome cs, gènes CREM et CREB).

\section{Régulation post-transcriptionnelle}

L'expression spécifique de certains gènes au cours de la spermatogenèse résulte d'un épis- 
sage alternatif de gènes exprimés dans les cellules somatiques. C'est le cas des lamines C2, B3 et de certaines enzymes du métabolisme énergétique (HK1 sa, sb, sc par exemple).

\section{Régulation traductionnelle}

La régulation traductionnelle de l'expression des gènes de la lignée germinale est particulièrement importante en fin de spermatogenèse alors que les phénomènes de transcription ont cessé quelques jours avant la spermiogenèse. La présence et la taille des régions 3' et 5' non codantes des ARNm (3' et 5' UTR) sont des éléments importants dans cette régulation.

\section{Rôle de l'extrémité 5' des ARN}

- Rôle de séquences régulatrices dans la région 5'UTR des ARN

En ce qui concerne certains gènes transcrits dans les spermatocytes, tels que la PGK2 et la proacrosine, des expériences effectuées suggèrent l'existence d'un mécanisme de régulation traductionnelle impliquant des séquences de la région 5 '.

Les gènes de la PGK2 et de la proacrosine sont déjà transcrits dans les spermatocytes pachytènes mais leurs ARNm vont être traduits seulement au stade de spermatide ronde. Les transcrits de la PGK2 sont absents des polysomes dans les spermatocytes pachytènes mais s'associent à ces derniers de manière importante dans les spermatides rondes [62].

La régulation de l'expression du gène de la proacrosine a été étudiée chez la souris transgénique [147]. L'expérience suggère la présence de séquences pouvant lier des protéines spécifiques des cellules germinales qui inhiberaient la traduction dans les spermatocytes ou l'activeraient dans les spermatides. Cette hypothèse est confortée par des expériences de retard sur gel qui ont montré que l'extrémité 5' pouvait lier de façon spécifique des protéines d'extraits cytoplasmiques testiculaires [148].

La Superoxide Dismutase (SOD) est également soumise à une régulation post-transcriptionnelle dans les cellules germinales mâles. Sa fonction est de protéger les cellules des altérations causées par les ROS. Cependant, son expression doit être étroitement régulée car une surexpression peut être responsable de trisomie 21 [11] et une sous-expression peut conduire à une infertilité masculine [7]. Chez la souris, de multiples ARNm de la SOD-1 ont été détectés : le plus petit est présent dans les cellules somatiques et durant les stades précoces de la spermatogenèse tandis que les deux ARNm les plus grands (se distinguant par la présence d'une séquence supplémentaire de 114 nucléotides dans leur région 5') sont spécifiques des cellules germinales post-méiotiques $[68,93]$. Une protéine de liaison à l'ARN de 65 $\mathrm{kb}$ est capable de se lier à cette séquence supplémentaire et d'empêcher la traduction de l'ARNm de la SOD-1 in vitro [69]. Ainsi, l'interaction protéique avec cette séquence des ARNm spécifiques des cellules germinales post-méiotiques de la SOD-1 règle avec précision la synthèse de la SOD-1 aux stades tardifs de la spermatogenèse.

\section{Rôle de l'extrémité 3' UTR des ARN}

La régulation traductionnelle est également médiée par l'extrémité 3'UTR.

- Rôle de la queue polyA

La taille des transcrits est dictée par la longueur de leur queue polyA qui en retour leur confêre leur compétence traductionnelle.

Ainsi, les gènes codant pour les protéines nucléaires basiques TP1, TP2, P1 et P2 sont transcrits dans les spermatides rondes et les spermatides en élongation. Ces $\mathrm{ARNm}$ sont alors stockés pendant plusieurs jours dans les particules ribonucléoprotéiques du cytoplasme, où leur traduction est réprimée par de longues queues polyA. Ces transcrits sont ensuite activement traduits après un raccourcissement de la queue polyA consécutif à une déadénylation. Ainsi, les ARNm stockés et non associés aux polysomes sont longs et homogènes en taille alors que les formes qui vont être traduites (associées aux polysomes) sont plus courtes et hétérogènes du fait du raccourcissement de la queue polyA au moment de l'activation traductionnelle [103]. Cette déadénylation partielle pourrait faciliter l'activation des ARNm stockés ou bien représenter une particularité de la régulation traductionnelle au cours de la spermiogenèse. En effet, l'activité traductionnelle est habituellement promue 
par un allongement de la queue polyA [167, 218]. Toutefois, des ARNm de P1 de grande taille ont également été retrouvés dans la fraction polysomale des spermatides en voie d'allongement [103], ce qui suggère que le raccourcissement des ARNm ne serait pas indispensable au processus traductionnel et pourrait simplement traduire une dégradation débutante des ARNm.

A l'inverse, les ARNm polysomaux des cellules préméiotiques et méiotiques codant pour l'ornithine carboxylase, la LDH C et le cytochrome c montrent un allongement de la queue polyA [79]. En ce qui concerne le cytochome c, des transcrits longs ont été détectés dans la fraction polysomale des spermatocytes pachytènes de souris adulte (lieu de traduction des ARN) tandis que des transcrits plus courts ont été retrouvés dans les ribonucléoprotéines isolées des spermatides rondes [où les ARN sont stockés]. Les 2 types de transcrits differrent uniquement par la taille de leur queue polyA respective et les taux d'enzymes les plus importants sont retrouvés dans les cellules présentant le transcrit long en quantité importante.

- Rôle des séquences régulatrices dans la région 3'UTR

Le gène de la PGK2 est transcrit à partir du stade spermatocyte pachytène mais la traduction des ARNm s'effectue seulement au stade de spermatide ronde chez la souris. Les expériences effectuées chez des souris transgéniques (gène comprenant uniquement les séquences 5 ' du codon d'initiation de la traduction du gène humain PGK2) ne mettent pas en évidence de retard dans la traduction de l'ARNm. Ceci suggère que les séquences absentes de la construction, c'est à dire la région codante et/ou l'extrémité 3'UTR possèdent des séquences régulatrices empêchant la traduction prématurée du transcrit [168].

- Interaction de l'extrémité 3'UTR avec des facteurs trans

Le testicule constitue une source importante de protéines de liaison à l'ARN. Des éléments agissant en cis ont été identifiés dans la région 3'UTR des ARNm des protamines 1 et 2. Des facteurs trans se liant à ces éléments ont également été mis en évidence [112, 113].
- Les séquences interagissant avec les protéines

Kwon et Hecht [112] ont identifié deux éléments hautements conservés ( $\mathrm{Y}$ et $\mathrm{H}$ ) au niveau de l'extrémité 3'UTR de l'ARNm de la protamine 2 (site de liaison de 35 nucléotides environ). Ces éléments interagissent avec des protéines cytoplasmiques dans le testicule. Il existe également un site d'interaction protéique au niveau de l'ARNm de la protamine 1 (région limitée à 22 nucléotides).

La comparaison des régions 3'UTR des ARN de PRM1 et PRM2 interagissant avec des protéines révèle la présence d'une courte homologie de séquence, pouvant constituer un élément important de liaison [54]. Par, ailleurs, des expériences de compétition indiquent que les mêmes protéines se lient à la région 3'UTR de PRM1 PRM2.

\section{Les protéines de liaison à l'ARNm}

\section{- La TB-RBP(testis-brain RNA binding pro- tein)}

La TB-RBP se lie à des séquences conservées de la région 3'UTR des ARNm d'un grand nombre de protéines testiculaires soumises à une régulation traductionnelle [79]. Cette protéine est présente en quantité importante dans le noyau des spermatocytes au stade pachytène et dans le cytoplasme des spermatides rondes. La TB-RBP pourrait assurer la répression traductionnelle des $\mathrm{ARNm}$, ainsi que leur transport et leur localisation dans les cellules germinales mâles.

\section{- $R B M$}

Les gènes de la famille RBM constituent des gènes candidats pour le locus $\mathrm{AZFb}$ du chromosome Y [91]. De nombreuses copies sont portées par le chromosome $\mathrm{Y}$, mais seuls les gènes RBM1 (constitué de 12 exons) et RBM2 semblent actifs et codent pour une protéine de liaison à l'ARN, spécifiquement retrouvée dans le testicule.

La protéine RBM est une protéine nucléaire spécifique des cellules germinales [50], exprimée par les spermatogonies, les spermatocytes I et les spermatides rondes [51]. Elle présente une forte homologie avec la superfamille des protéines de liaison à l'ARN (heterogeneous nuclear ribonucleoprotein (hnRNP family). De 
plus, la colocalisation de cette protéine avec des facteurs d'épissage dans le noyau suggère un rôle important dans la transformation des ARN [26, 51]. Dans les spermatogonies et les spermatocytes, la protéine RBM est localisée dans des zones nucléaires riches en facteurs d'épissage. Dans les spermatocytes aux stades tardifs, RBM et les facteurs d'épissage se dissocient (les facteurs d'épissage se concentrent dans une zone alors que RBM est réparti dans l'ensemble du nucléoplasme). Dans les spermatides rondes, les facteurs d'épissage sont localisés dans une zone majeure et d'autres sites plus petits, ainsi que dans l'ensemble du nucléoplasme. En revanche, RBM ne se localise plus en des points précis, mais est uniformément distribué dans tout le nucléoplasme [176].

\section{- $D A Z$}

Le gène $D A Z$ est situé dans la région Yq11 et constitue un gène candidat pour $\mathrm{AZF}$. Le gène DAZ code pour une protéine de 366 acides aminés comportant dans sa partie carboxy-terminale 7 répétitions en tandem de 24 acides aminés (appelées répétitions DAZ) et dans sa partie amino-terminale le motif de reconnaissance à l'ARN RNP/RRM (ribonucléoprotéine/RNA recognition motif) [165]. Le gène $\mathrm{DAZ}$ existe en plusieurs copies au niveau de la région distale 6 [178]. Comme dans le cas de RBM, la transcription de DAZ est limitée à la lignée germinale mâle.

La transcription de l'unité DAZ est complexe, avec la présence de pseudo-exons c'est à dire d'exons non fonctionnels comportant des sites d'épissage dégénérés en 5' et 3' qui sont excisés lors de la transformation des pré-ARNm de DAZ [178]. Chaque individu possède de multiples gènes $\mathrm{DAZ}$ dont le nombre de copies, mais aussi l'ordre varient, avec au minimum 3 gènes activement transcrits [224].

Le groupe DAZ sur le chromosome Y proviendrait d'un gène autosomal transposé, amplifié plusieurs fois et dégénéré.

La protéine DAZ est exprimée essentiellement au niveau des spermatogonies, plus rarement dans les spermatocytes I (stade L/Z).

Le gène $\mathrm{DAZ}$ présente $35 \%$ d'homologie avec le gène spécifique de gonade BOULE trouvé chez la drosophile [46], qui joue un rôle dans l'en- trée des spermatocytes en méiose et dont la déficience entraîne une stérilité chez le mâle.

Cette région du chromosome $\mathrm{Y}$ est délétée chez 4 à $13 \%$ des patients présentant une oligozoospermie sévère $[144,145,160,166]$. L'existence d'une oligospermie malgré la présence d'une délétion indique que $\mathrm{DAZ}$ n'est pas indispensable à l'achèvement de la spermatogenèse.

Un gène homologue de DAZ, DAZLA, a été identifié sur le bras court du chromosome 3, suggérant l'existence d'autres gènes autosomaux intervenant dans la spermatogenèse. $[178,225]$.

\section{CONCLUSION}

Les nombreuses données concernant les gènes de la spermatogenèse et leur régulation témoignent de la complexité moléculaire de ce processus particulièrement original puisqu'il aboutit à la formation de cellules haploïdes qui subissent une maturation morphologique spectaculaire. Il n'est donc pas étonnant d'observer dans le testicule des expressions géniques spécifiques et des modes de régulation géniques différents des autres organes.

Les mécanismes essentiels au bon déroulement de la spermatogenèse comportent :

-L'équilibre indispensable entre, d'une part la multiplication des cellules germinales liée au système c-kit/SCF et d'autre part l'apoptose dont la régulation est assurée par des gènes pro- et anti-apoptotiques. L'apoptose permet non seulement l'élimination des cellules germinales anormales mais également de celles qui, en excès, ne pourraient être soutenues par les cellules de Sertoli.

- L'expression d'une grande variété de gènes nécessaire au bon déroulement et à l'achèvement des deux divisions méiotiques. Plusieurs familles de gènes interviennent dans l'aboutissement de ce processus. Les gènes du cycle cellulaire permettent le déroulement des 2 divisions méiotiques successives. Certains gènes assurent la réparation de l'ADN et régulent les phénomènes de recombinaison méiotique qui est possible grâce à la mise en place de protéines composant le com- 
plexe synaptonémal. Les modifications nucléaires sont possibles grâce aux protéines structurales, telles que les lamines qui maintiennent l'intégrité de la structure nucléaire.

- Le remodelage de la structure chromatinienne au cours de la spermatogenèse. Celui ci aboutit à une condensation nucléaire assurée par l'expresssion séquentielle des protéines basiques spécifiques de liaison à l'ADN (protéines de transition et protamines). Ces modifications permettent la nécessaire protection de l'ADN du noyau du spermatozoïde et sont impliquées dans l'arrêt de l'activité transcriptionnelle qui est observée.

- La production d'isoformes spécifiques indispensables à la compensation de la répression de l'expression des gènes liés à l'X (pdha 1 , pgk 1) et à la régulation fine de l'expression de gènes essentiels à l'achèvement de la spermatogenèse (système CREM/CREB et régulation des gènes des protéines de transition et des protamines).

- Une régulation transcriptionnelle complexe, assurée essentiellement par des facteurs protéiques eux-mêmes soumis à une régulation testiculaire spécifique et une régulation traductionnelle possible grâce aux séquences régulatrices 5' et 3' UTR.

Ces deux mécanismes de régulation permettent d'assurer la séquence des évènements moléculaires spatio-temporels indispensables au bon déroulement de la spermatogenèse.

A l'heure où les techniques de fécondation in vitro avec micromanipulation se sont répandues, notre ignorance de l'étiologie de nombreuses stérilités masculines pose la question des risques pour les enfants nés après la mise en œuvre de ces techniques et incite à poursuivre les efforts de recherche. Outre l'intérêt fondamental d'une meilleure connaissance des signaux de spécificité testiculaire, que ce soit au niveau des promoteurs, de l'épissage, de la polyadénylation, de la stabilité et de la traductibilité des messagers, une meilleure connaissance de l'expression des gènes au cours de la spermatogenèse est nécessaire pour appréhender la physiopathologie de certaines stérilités masculines.

\section{REFERENCES}

1. ALCIVAR A.A., TRASLER J.M., HAKE L.E., SALEHI-ASHTIANI K., GOLDBERG E., HECHT N.B. DNA methylation and expression of the genes coding for lactate deshydrogenases $\mathrm{A}$ and $\mathrm{C}$ during rodent spermatogenesis. Biol. Reprod. , 1991, 44 : 527-535.

2. ALCIVAR A.A., HAKE L.E., HECHT N.B . DNA polymerase-b and poly[ADP]ribose polymerase mRNAs are differentially expressed during the development of male germinal cells. Biol. Reprod., 1992, 46 : 201-207.

3. ALLAN D.J., HARMON B.V., KERR J.F.R. Cell death in spermatogenesis. In : Perspectives on Mammalian Cell Death [ed. C.S. POTTEN], London : Oxford University Press. 1987 : 229-258.

4. ALLEN J.W., COLLINS B.W., MERRICK B.A. et al. HSP70-2 is part of the synaptonemal complex in mouse and hamster spermatocytes. Chromosoma, 1996, 104 : 414-421.

5. ALMON E., GOLDFINGER N., KAPON A., SCHWARTZ D., LEVINE A.J., ROTTER V. Testicular tissue-specific expression of the p53 suppressor gene. Dev. Biol., 1993, 156 : 107-116.

6. ALTHAUS F.R., RICHTER C. ADP-ribosylation of proteins : enzymology and biological significance. Mol. Biol. Biochem. Biophys., 1987, 37 : 1-125.

7. ALVAREZ J.G., STOREY B.T. Evidence for increased lipid peroxidative damage and loss of superoxide dismutase activity as a model of sublethal cryodamage to human sperm during cryopreservation. J. Androl., 1992, $13: 232-241$.

8. ANDERSEN B., PEARSE R.V., SCHLEGEL P.N. et al. Sperm-1 : a POU-domain gene transiently expressed immediatly before meiosis I in the male germ cell. Proc. Natl. Sci. Acad. USA, 1993, 90 : 1108411088.

9. ANGELOPOULOU R., LEVENTIS A. Genes implicated in the regulation of apoptosis. Arch. Hellenic. Med., 1997, $14: 367$.

10. ARCECI R.J., KING A.A., SIMON M.C., ORKIN S.H., WILSON D.B. Mouse GATA-4 : a retinoic acidinducible GATA-binding transcription factor expressed in endodermally derived tissues and heart. Mol. Cell. Biol., 1993, 13 : 2235-2246.

11. AVRAHAM K.B., SCHICKLER M., SAPOZNIKOV D., YOKAM R., GRONER Y. Down's syndrome : abnormal neuromuscular junction in tongue of transgenic mice with elevated level of human superoxide dismutase. Cell, 1988, 54 : 823-829.

12. BAKER S.M., BRONNER C.R., ZHANG L. et al. Male mice defective in the DNA mismatch repair gene PMS2 exhibit abnormal chromosome synapsis in meiosis. Cell, 1995, $82: 309-319$.

13. BAKER S.M., PLUG A.W., PROLLA T.A., et al. Involvement of mouse Mlh1 in DNA mismatch repair and meiotic crossing over. Nat. Genet., 1996, 13 [3] : 336-342. 
14. BARLOW C., HIROTSUNE S., PAYLOR R. et al. Atm-deficient mice : a paradigm of ataxia telangiectasia. Cell, 1996, $85:$ 159-171.

15. BARTKE A., Editorial : apoptosis of male germ cells, a generalized or a cell type-specific phenomenon? Endocrinology, 1995, 136, 3-4.

16. BERNARDS R., SCHACKEFORD G.M., GERBER M.R. Structure and expression of the murine retinoblastoma gene and characterization of its encoded protein. Proc. Natl. Sci. Acad. USA, 1989, 86 : 64746478.

17. BEUMER T.L., DE ROOIJ D.G. Regulation of apoptosis in the testis. In : Male Sterility for motility disorders : etiological factors and treatment. Edited by HamamahS., Mieusset R., Olivennes F., JOUANNET P., FRYDMAN R. New York : Springer Verlag ; 1998.

18. BEUMER T.L., ROEPERS-GAJADIEN H.L., GADEMAN I.S. et al. The role of the tumor suppressor p53 in spermatogenesis. Cell Death Differ., 1998, 5 : 669677.

19. BILLIG H., FURUTA I., RIVIER C., TAPANAINEN J., PARVINEN M., HSUEH A.J.W. Apoptosis in testis germ cells : developmental changes in gonadotropin dependence and localization to selective tubule stages. Endocrinology, 1995, $136: 5-12$.

20. BISHOP D.K., PARK D., ZU L., KLECKNER N. A meiosis-specific yeast homolog of $\mathrm{E}$. coli recA required for recombination, synaptonemal complex formation and cell cycle progression. Cell, 1992, $69: 439$ 456.

21. BLANCHARD K.T,, LEE J., BOEKELHEIDE K. Leuprolide, a gonadotropin-releasing hormone agonist, reestablishes spermatogenesis after 2,5-hexanedione-induced irreversible testicular injury in the rat, resulting in normalized stem cell factor expression. Endocrinology, 1998, 139 : 236-244.

22. BRANCIFORTE D., MARTIN S.L. Developmental and cell specificity of LINE-1 expression in mouse testis : implications for transposition. Mol. Cell. Biol., 1994, 14 : 2584-2592.

23. BRANDFORD W.W., ZHAO G.Q, VALERIUS M.T. et al. Spx-1, a novel $X$-linked homeobox gene expressed during spermatogenesis. Mech. Dev., 1997, 65 : 87-98.

24. BROCARD J., KASTNER P., CHAMBON P. Two novel RXRa isoforms from mouse testis. Biochem. Biophys ; Res. Commun., 1996, 229 : 211-218.

25. BROCENO C., RUIZ P., VILARO S., PONS G. The muscle-specific phosphoglycerate mutase gene is specifically expressed in testis during spermatogenesis. Eur. J. Biochem., 1995, 227 : 629-635.

26. CACERES J.F., STAMM S., HELFMAN D.M., KRAINER A.R. Regulation of alternative splicing in vivo by overexpression of antagonistic splicing factors. Science, 1994, 265 : 1706-1709.

27. CALENDA A., ALLENET B., ESCALIER D., BACH
J.F., GARCHON H.J. The meiosis-specific Xmr gene product is homologous to the lymphocyte Xlr protein and is a component of the XY body. EMBO J., 1994, $13: 100-109$.

28. CHAPMAN D.L., WOLGEMUTH D.J. Isolation of the murine cyclin B2 cDNA and characterization of the lineage and temporal specificity of expression of the B1 and B2 cyclins during oogenesis, spermatogenesis and early embryogenesis. Development, 1993, 118 : 229-240.

29. CHAPMAN D.L., WOLGEMUTH D.J. Regulation of M-phase promoting factor activity during development of germ cells. Dev. Biol., 1994, 165 : 500-506.

30. CHEN Q., PEARLMAN R.E., MOENS P.B. Isolation and characterization of a cDNA encoding a synaptonemal complex protein. Biochem. Cell Biol. 1992, 70: 1030-1038.

31. CHEN Q., TOMKINSON A.E., RAMOS W. et al. Mammalian DNA ligase III : molecular cloning, chromosal localization and expression in spermatocytes undergoing meiotic recombination. Mol. Cell. Biol., 1995, $15: 5412-5422$.

32. CHINNAIYAN A.M., DIXIT V.M. The cell-death machine. Curr. Biol., 1996, 6 : 555-562.

33. CHIU M.L., IRVIN J.L. Absence of histone H2B in nucleosomes containing histone $\mathrm{TH} 2 \mathrm{~B}$ and interaction of immunoglobulin with nucleosomes. Arch . Biochem. Biophys., 1986, 244 : 42-49.

34. CHOI Y.C., CHAE C.B. DNA hypomethylation and germ cell-specific expression of testis-specific H2B histone gene. J. Biol. Chem., 1991, 266 : 2050420511.

35. CHOI Y.C., CHAE C.B. Demethylation of somatic and testis-specific histone $\mathrm{H} 2 \mathrm{~A}$ and $\mathrm{H} 2 \mathrm{~B}$ genes in F9 embryonal carcinoma cells. Mol. Cell. Biol., 1993, 13: 5538-5548.

36. CONCHA I.I., FIGUEROA J., CONCHA M.I., UEDA K. BURZIO L.O. Intracellular distribution of poly[ADP-ribose] synthetase in rat spermatogenic cells. Exp. Cell Res., 1989, 180 : 353-366.

37. DADOUNE J.P. The nuclear status of human sperm cells. Micron, 1995, 26 : 323-345.

38. DAHL H.H.M., BROWN R.M., HUTCHINSON W.M., MARAGOS C., BROWN G.K. Atestis-specific form of the human pyruvate deshydrogenase E1a subunit is coded for by an introless gene on chromosome 4 . Genomics, 1990, 8 : 225-232.

39. DELMAS V., VAN DER HOORN F., MELLSTROM B., JEGOU B., SASSONE-CORSI P. Induction of CREM activator proteins in spermatids : downstream targets and implications for haploïd germ cell differenciation. Mol. Endocrinolol., 1993, 7 : 1502-1514.

40. DE MURCIA G., MENESSIER-DE MURCIA J. Poly[ADP-ribose] polymerase : a molecular nick-sensor. Trends Biochem. Sci., 1994, 19 : 172-176. 
41. DIX D.J., ROSARIO-HERRLE M., GOTOH H. Developmentally regulated expression of $\mathrm{Hsp} 70$ and a Hsp70-2/lacZ transgene during spermatogenesis. Dev. Biol. , 1996, 174 : 310-321.

42. DIX D.J., ALLEN J.W., COLLINS B.W. et al. Targeted gene disruption of Hsp70-2 results in failed meiosis, germ cell apoptosis, and male infertility. Proc. Natl. Acad. Sci. USA, 1996, 93, 3264-3268.

43. DOBSON M.J., PEARLMAN R.E., KARAISKAKIS A., SPYROPOULOS B., MOENS P.B. Synaptonemal complex proteins : occurrence, epitope mapping and chromosome disjunction. J. Cell Sci., 1994, 107 : 2749-2760.

44. DOMENJOUD L., FRONIA C., UHDE F., ENGEL W. Sequence of human protamine $2 \mathrm{cDNA}$. Nucleic Acids Res., 1988, $16: 7733$.

45. DRABENT B., BODE C., BRAMLAGE B., DOENECKE D. Expression of the mouse testicular histone gene H1t during spermatogenesis. Histochem. Cell. Biol., 1996, 106 : 247-251.

46. EBERHART C.G., MAINES J.Z., WASSERMAN S.A. Meiotic cell requirement for a fly homologue of human deleted in azoospermia. Nature, 1996, 381 : 783-785.

47. EDDY E.M., O'BRIEN D.A. The spermatozoon. In : E. Knobil and J.D. Neill eds. The physiology of reproduction. New-York, Raven Press, 1994, vol. I : 29-77.

48. EDDY E.M., WELCH J.E., O'BRIEN D.A. Gene expression during spermatogenesis. In : de Kretser D. [ed]. Molecular biology of the male reproductive system. Academic Press, London, 1993 : 181-218.

49. EDELMANN W., COHEN P.C., KANE M. Meiotic pachytene arrest in MLH1-deficient mice. Cell, 1996, $85: 1125-1134$.

50. ELLIOTT D.J., MILLAR M.R., O'GHENE K., et al. Expression of RBM in the nuclei of human germ cells is dependant on a critical region of the $\mathrm{Y}$ chromosome long arm. Proc. Natl. Acad. Sci. USA, 1997, 94 : 38483853.

51. ELLIOTT D.J., O'GHENE K., HARGREAVE T.B., CHANDLEY A.C., COOKE H.J. Dynamic changes in the subnuclear organisation of pre-mRNA binding proteins and RBM during human germ cell development. J. Cell Sci., 1998, 111 [pt 9] : 1255-1265.

52. ELLIS R.E., YUAN J.Y., HORVITZ H.R. Mechanisms and function of cell death. Annu. Rev. Cell. Biol., 1991, $7: 663-698$.

53. ELSON A., WANG Y., DAUGHERTY C.J. et al. Pleiotropic defects in ataxia-telangiectasia proteindeficient mice. Proc. Natl. Acad. Sci. USA, 1996, 93 : 13084-13089.

54. FAJARDO M.A., BUTNER K.A., LEE K., BRAUN R.E. Germ cell-specific proteins interact with the 3' untranslated regions of Prm-1 and Prm-2 mRNA. Dev. Biol., 1994, 166 : 643-653.
55. FOULKES N.S., MELLSTROM B., BENUSIGLIO E., SASSONE-CORSI P. Developmental switch of CREM function during spermatogenesis from antagonist to activator. Nature, 1992, $355: 80-84$.

56. FOULKES N.S., SCHLOTTER F., PEVET P., SASSONE-CORSI P. Pituitary hormone FSH directs the CREM functional switch during spermatogenesis. Nature, 1993, $362:$ 264-267.

57. FUNDELE R., WINKING H., ILLMENSEE K., JAGERBAUER E.M. Developmental activation of phosphoglycerate mutase- 2 in the testis of the mouse. Dev. Biol., 1987, 124 : 562-566.

58. FURUCHI T., MASUKO K., NISHIMUNE Y., OBINATA M., MATSUI Y. Inhibition of testicular germ cell apoptosis and differenciation in mice misexpressing Bcl-2 in spermatogonia. Development, 1996, 122: 1703-1709.

59. FURUKAWA K., INAGAKI H., HOTTA Y. Identification and cloning of an mRNA coding for a germ cellspecific A-type lamin in mice. Exp. Cell. Res.,1994, $212: 426-430$.

60. FURUKAWA K., HOTTA Y. cDNA cloning of a germ cell specific lamin B3 from mouse spermatocytes and analysis of its function by ectopic expression in somatic cells. EMBO J., 1993, $12:$ 97-106.

61. GERACE L., BURKE B. Functional organization of the nuclear enveloppe. Annu. Rev. Cell. Biol., 1988, 4 : 335 .

62. GOLD B ;, FUJIMOTO H., KRAMER J.M., ERICKSON R.P., HECHT N.B. Haploid accumulation and translational control of phosphoglycerate kinase-2 messenger RNA during mouse spermatogenesis. Dev. Biol., 1983 : 98 : 392-399.

63. GOTO M., KOJI T., MIZUNO K. et al. Transcription switch of two phosphoglycerate kinase genes during spermatogenesis as determined with mouse testis sections in situ. Exp. Cell Res., 1990, 186 : 273-278.

64. GRIMES S., WEISZ-CARRINGTON P., DAUM H. et al. A rat histone $\mathrm{H} 4$ gene closely associated with the testis-specific H1t gene. Exp. Cell . Res., 1987, 173 : 534-545.

65. GRIMES S.R., WOLFE S.A., KOPPEL D.A. Temporal correlation between the appearance of testis-specific DNA-binding proteins and the onset of transcription of the testis-specific histone H1t gene. Exp. Cell Res., 1992, $201: 216-224$.

66. GRIPPO P., GEREMIA R., LOCOROTONDO C., MONESI V. DNA-dependant DNA polymerase species in male germ cells of the mouse. Cell Differ., $1978,7: 237-248$.

67. GRISWOLD M.D. Action of FSH on mammalian Sertoli cells. In : Russel L.D., GRISWOLD M.D., eds. The Sertoli cell. 1993. Clearwater : Coche river : 493508.

68. GU W., MORALES C., HECHT N.B. In male mouse germ cells $\mathrm{Cu}$-Zn superoxide dismutase utilizse alter- 
native promoters which produce multiple transcripts with different translation potential. J. Biol. Chem., 1995, 270:236-243.

69. GU W., HECHT N.B. Translation of a testis-specific $\mathrm{Cu} / \mathrm{Zn}$ superoxide dismutase mRNA [SOD-1] is regulated by a $65 \mathrm{kDa}$ protein which binds to its 5' untranslated region. Mol. Cell. Biol., 1996, 16 : 45354543 .

70. HAAF T., GOLUB E.I., REDDY G., RADDING C.M., WARD D.C. Nuclear foci of mammalian Rad51 recombination protein in somatic cells after DNA damage and its localization in synaptonemal complexes. Proc. Natl. Acad. Sci. USA, 1995, 92 : 22982302.

71. HABU T., TAKI T., WEST A., NISHIMUNE Y., MORITA T. The mouse and human homologs of DMC1, the yeast meiosis-specific homologous recombination gene, have a common unique form of exonskipped transcripts in meiosis. Nucleic Acids Res., 1996, $24: 470-477$.

72. HAKE L.E., HECHT N.B. Utilization of an alternative transcription initiation site of somatic cytochrome $\mathrm{c}$ in the mouse produces a testis-specific cytochrome $\mathrm{c}$ mRNA. J. Biol. Chem., 1993, 268 : 4788-4797.

73. HAKOVIRTA H., YAN W., KALEVA M. et al. Function of stem cell factor as a survival factor of spermatogonia and localization of messenger ribonucleic acid in the rat seminiferous epithelium. Endocrinology, 1999, 140 [3] : 1492-1498.

74. HANDEL M.A., PARK C., KOT M. Genetic control of sex-chromosome inactivation during male meiosis. Cytogenet. Cell Genet., 1994, 66 : 83-88.

75. HASEGAWA M., ZHANG Y., NIIBE H. TERRY N.H.A., MEISTRICH M.L. Resistance of differentiating spermatogonia to radiation-induced apoptosis and loss in p53-deficient mice. Radiat. Res., 1998, 149 : 263-270.

76. HECHT N.B., FARREL D., WILLIAMS J.L. DNA polymerase in mouse spermatogenic cells separated by sedimentation velocity. Biochim. Biophys. Acta, 1979, $561: 358-368$.

77. HECHT N.B., FARREL D., DAVIDSON D. Changing DNA polymerase activities during the development of the testis in the mouse. Dev. Biol., 1976, 48 : 56-66.

78. HECHT N.B., PARVINEN M. DNA synthesis catalized by endogenous templates and DNA-dependant DNA polymerase in spermatogenetic cells from rat. Exp. Cell Res., 1981, 135 : 103-114.

79. HECHT N.B. Molecular mechanisms of male germ cell differenciation. Bioessays, 1998, 20 : 555-561.

80. HECHT N.B. Mammalian protamines and their expression. In : Hnilica L., Stein G., Stein J. [eds]. Histones and other basic nuclear proteins. CRC Press, Boca Raton, 1989a : 347-373.

81. HECHT N.B. The molecular biology of spermatogenesis : regulation of mammalian protamines from gene to proteins. In : Serio M. [ed]. Perspectives in andrology. Serono Symposia. Raven Press, 1989b : 25-35.

82. HECHT N.B. Gene expression during spermiogenesis. In : Hamilton D.W., Waites G.M.H. [eds]. Cellular and molecular evnts in spermiogenesis. Cambridge University Press, 1990a : 265-283.

83. HECHT N.B. regulation of haploid expressed genes in male germ cells. J. Reprod. Fertil., 1990b, 88 : 679693.

84. HENRIKSEN E., HAKOVIRTA H., PARVINEN M. Testosterone inhibits and induces apoptosis in rat seminiferous in a stage-specific manner : in situ quantification in sqash preparations after administration of ethane dimethane sulfonate. Endocrinology, 1995, $136: 3285-3291$.

85. HENRIKSSON M., LUSCHER B., Proteins of the Myc network : essential regulators of cell growth and differenciation. Adv. Cancer Res., 1998, 68 : 109-182.

86. HESS R.A., MILLER L.A., KIRBY J.D., MARGOLIASH E., GOLDBERG E. Immunoelectron microscopic localization of testicular and somatic cytochromes c in the seminiferous epithelium of therat. Biol. Reprod., 1993, 48 : 1299-1308.

87. HUH N.E., HWANG I., LIM K., YOU K.H., CHAE C.B. Presence of a bi-directional $\mathrm{S}$ phase-specific transcription regulatory element in the promoter shared by testis-specific TH2A and TH2B genes. Nucleic Acids Res., 1991, 19 : 93-98.

88. HUMMELKE G.C., MEISTRICH M.L., COONEY A.J. Mouse protamine genes are candidate targets for the novel orphan nuclear receptor, germ cell nuclear factor. Mol. Reprod. Dev., 1998, 50 : 396-405.

89. INOHARA N., GOURLEY T.S., CARRIO R. et al. Diva, a Bcl-2 homologue that binds directly to Apaf-1 and induces BH3-independant cell death. J. Biol. Chem., 1998, 273 [49] : 32479-32486.

90. ITO E., TOKI T., ISHIHARA H. Erythroïd transcription factor GATA-1 is abundantly transcribed in mouse testis. Nature, 1993, $362: 466-468$.

91. JOBLING M.A., SAMARA V., PANDYA A. et al. Recurrent duplication and deletion polymorphisms on the long arm of the $\mathrm{Y}$ chromosome in normal males. Hum. Mol. Genet., 1996, 5 [11] : 1767-1775.

92. JOHNSON R.S., SPIEGELMAN B.M., PAPAIOANNOU V., Pleiotropic effects of a null mutation in the c-fos proto-oncogene. Cell, 1992, 71 : 577-586.

93. JOW W.W., SCHLEGEL P.N., CICHON Z., PHILLIPS D., GOLDSTEIN M., BARDIN C.W. Identification and localization of copper-zinc superoxide dismutase gene expression in rat testicular development. J. Androl., 1993, 14 : 439-447.

94. JURGENSMEIER J.M., XIE Z., DEVERAUX Q., ELLERBY L., BREDESEN D., REED J.C. Bax directly induces release of cytochrome $\mathrm{c}$ from isolated mitochondria. Proc. Natl. Sci. USA, 1998, 95, 49975002 . 
95. KANEI-ISHII C., NOMURA T., SARAI A. et al. Structure and function of the proteins encoded by the myb gene family. Curr. Top. Microbiol. Immunol., 1996, $211: 89-98$.

96. KANGASNIEMI M., KAIPIA A., TOPPARI J., PERHEENTUPA A., HUHTANIEMI I., PARVINEN M. Cellular regulation of follicle-stimulating hormone binding in rat seminiferous tubules. J. Androl., 1990, $11: 336-343$.

97. KASTNER P., CHAMBON P., LEID M. Role of nuclear retinoic acid receptors in the regulation gene expression. In : Blomhoff R. [ed.]. Vitamin A in health and disease. New-York : Marcel Dekker Inc., 1994: 189-238.

98. KATZ D., NEIDERBERGER C., SLAUGHTER G.R., COONEY A.J. Characterization of germ cell specific expression of the orphean nuclear receptor, GCNF. Endocrinology, 1997, $138: 4364-4372$.

99. KEEGAN K.S., HOLTZMAN D.A., PLUG A.W. et al. The Atr and Atm proteins associate with different sites along meiotically pairing chromosomes. Genes Dev., 1996, 10 : 2423-2437.

100. KHADAKE J.R., RAO M.R.S. DNA- and chromatin-condensing properties of rat testes $\mathrm{Hla}$ and H1t compared to those of rat liver H1bdec : H1t is a poor condenser of chromatin. Biochemistry, 1995, $34: 15792-15801$.

101. KIM Y.J., HWANG I., TRES L., KIERZENBAUM A.L., CHAE C.B. Molecular cloning and differential expression of somatic and testis-specific H2B histone genes during rat spermatogenesis. Dev. Biol., 1987, $124: 23-34$.

102. KISTLER M., SASSONE-CORSI P., KISTLER S.W. Identification of a functional cAMP response element in the 5'-flanking region of the gene for transition protein [TP1], a basic chromosomal protein of mammalian spermatids. Biol. Reprod., 1994, 51: 1322-1329.

103. KLEENE K.C. Poly[A] shortening accompanies the activation of translation of five mRNAs during spermiogenesis in the mouse. Development, 1989, $106: 367-373$.

104. KLEENE K.C. Patterns of translational regulation in the mammalian testis. Mol. Reprod. Dev., 1996, $43: 268-281$.

105. KNUDSON C.M., TUNG K.S.K., TOURTELOTTE W.G., BROWN G.A.J., KORSMEYER S.J. Bax-deficient mice with lymphoid hyperplasia and male germ cell death. Science, 1995, $270: 96-99$.

106. KOJI T., JINNO A., MATSUSHIME H., SHIBUYA M., NAKANE P.K. In situ localization of male germ cell-associated kinase [mak] mRNA in adult mouse testis : specific expression in germ cells at stages around meiotic cell division. Cell Biochem. Funct., 1992, $10: 273-279$.

107. KOVALENKO O.V., PLUG A.W., HAAF T. et al.
Mammalian ubiquitin-conjugating enzyme Ubc9 interacts with Rad51 recombination protein and localizes in synaptonemal complexes. Proc . Natl. Sci. Acad. USA, 1996, $93:$ 2958-2963.

108. KRAJEWSKI S., BODRUG S., KRAJEWSKA M. et al.Immunohistochemical analysis of Mcl-1 protein in human tissues. Differential regulation of Mcl-1 and Bcl-2 production suggests a unique role for Mcl-1 in control of programmed cell death in vivo. Am. J. Pathol., 1995, 146 : 1309-1319.

109. KRAMER J.M., ERICKSON R.P. Immunofluorescent localization of PGK 1 and PGK 2 isoenzymes within specific cells of the mouse testis. Dev. Biol., $1981,87: 37-45$.

110. KREMER E.J., KISTLER W.S. Localization of mRNA for testis-specific histone H1t by in situ hybridization. Exp. Cell. Res., 1991, $197: 330-332$.

111. KUMARI M., STROUD J.C., ANJI A., MAC CARREY J.R. Differential appearance of Dnase Ihypersensitive sites correlates with differential transcription of Pgk genes during spermatogenesis in the mouse. J. Biol. Chem., 1996, $24: 14390-$ 14397.

112. KWON Y.K., HECHT N.B. Cytoplasmic protein binding to highly conserved sequences in the 3 ' untranslated region of mouse protamine $2 \mathrm{mRNA}$, a translationally regulated gene of male germ cells. Proc. Natl. Acad. Sci. USA, 1991, 88 : 3584-3588.

113. KWON Y.K., HECHT N.B. Binding of a phosphoprptein to the 3'untranslated region of the mouse protamine $2 \mathrm{mRNA}$ temporally represses its translation. Mol. Cell. Biol., 1993, 13 : 6547-6557.

114. LALLI E., SASSONE-CORSI P. Signal transduction and gene regulation : the nuclear response to cAMP. J. Biol. Chem., 1994, 269 : 17359-17362.

115. LAOIDE B.M., FOULKES M.S., SCHLOTER F. et al. The functional versatility of CREM is determined by its modular structure. EMBO J., 1993, 12 : 1179-1191.

116. LATHAM K.E., LITVIN J., ORTH J.M., PATEL B., METTUS R., REDDY P. Temporal patterns of Amyb and $\mathrm{B}$-myb gene expression during testis development. Oncogene, 1996, $13: 1161-1168$.

117. LEE J., RICHBURG J.H., YOUNKIN S.C., BOEKELHEIDE $\mathrm{K}$. The Fas system is a key regulator of germ cell apoptosis in the testis. Endocrinology, 1997, 138 [5] :2081-2088.

118. LELANNIC G., ARKHIS A., VENDRELY E., CHEVAILLIER P., DADOUNE J.P. Production, characterization and immunocytochemical applications of monoclonal antibodies to human sperm protamines. Mol. Reprod. Dev., 1993, 36 : 106-112.

119. LELE K., WOLGEMUTH D.J. The role of transcriptional control during spermatogenesis. J. Androl., 1998, 19 [6] : 639-649.

120. LEO C.P., HSU S.Y., MACGEE E.A., SALANOVA 
M., HSUEH A.J.W. DEFT, a novel death effector domain-containing molecule predominantly expressed in testicular germ cells. Endocrinology, 1998, 139 [12] : 4839-4848.

121. LESCOAT D., BLANCHARD Y., LAVAULT M.T., QUERNEE D., LELANNOU D. Ultrastructural and immunicytochemical study of P1 protamine localization in human testis. Andrologia, 1993, 25 : 93-99.

122. LI S.S.L., O'BRIEN D.A., HOU E.W., VERSOLA J., ROCKETT D.L., EDDY E.M. Differential activity and synthesis of lactate deshydrogenase isoenzymes A. [muscle], B [heart] and C [testis] in mouse spermatogenetic cells. Biol. Reprod., 1989, $40: 173-180$

123. LI Y., LEMAIRE P., BEHRINGER R.R. Esx-1, a novel $\mathrm{X}$ chromosome-linked homeobox gene expressed in mouse extra-embryonic tissues and male germ cells. Dev. Biol., 1997, 188 : 85-95.

124. LINDSEY J.S., WILKINSON M.F. Pem : a testosterone-and LH-regulated homeobox gene expressed in mouse Sertoli cells and epididymis. Dev. Biol., 1996, $179: 471-484$.

125. LIU J.G., YUAN L., BRUNDELL E., BJORKROTH B., DANEHOLT B., HÖÖG C. Localization of the $\mathrm{N}$-terminus of SCP1 to the central element of the synaptonemal complex and evidence for direct interactions between the $\mathrm{N}$-terminal of SCP1molecules organized head-to-head. Exp. Cell Res., 1996, $226: 11-19$.

126. LUO X., BUDIHARDJO I., ZOU H., SLAUGHTER C., WANG X.. Bid, a Bcl-2 interacting protein, mediates cytochrome $\mathrm{c}$ release from mitochondria in response to activation of cell surface death receptors. Cell, 1998, $94:$ 481-490.

127. MAC CARREY J.R., BERG W.M., PARAGIOUDAKIS S.J. et al. Differential transcription of Pgk genes during spermatogenesis in the mouse. Dev. Biol,, 1992, $154: 160-168$.

128. MAC CARREY J.R., THOMAS K. Human testisspecific PGK gene lacks introns and possesses characteristics of a processed gene. Nature [Lond.], 1987, $326: 501-505$.

129. MAC CARREY J.R. Evolution of tissue-specific gene expression in mammals. Bioscience, 1994, 44 : 20-27.

130. MANGELSDORF D.J., THUMMEL C., BEATO M. et al. The nuclear receptor superfamily : the second decade. Cell, 1995a, 83 : 835-839.

131. MANGELSDORF D.J., BORGMEYER U., HEYMAN R.A. et al. Characterization of three RXR genes that mediate the action of 9-cis retinoic acid. Genes Dev., 1992, 6 : 329-344.

132. MANGELSDORF D.J., EVANS R.M. The RXR heterodimers and orphan receptors. Cell, 1995b, 83 : 841-850.

133. MANOVA K., NOCKA K., BESMER P., BACHVAROVA R.F. Gonadal expression of c-kit encoded at the W locus of the mouse. Development, 1990, 110 : 1057-1069.
134. MANOVA K., HUANG E.J., ANGELES M. The expression pattern of the c-kit ligand in gonads of mice supports a role for the c-kit receptor in oocyte growth and in proliferation of spermatogonia. Dev. Biol., 1993, 157 : 85-99.

135. MEISTRICH M.L., BUCCI L.R., TROSTLEWEIGE P.K., BROCK W.A. Histone variants in rat spermatogonia and primary spermatocytes. Dev. Biol., 1985, 112 : 230-240.

136. MENEGAZZI M., GRASSI-ZUCCONI G., CARERERO-DE PRATI A. et al. Differential expression of poly[ADP-ribose] polymerase and DNA polymerase beta in rat tissue. Exp. Cell Res., 1991, 197 : 66-74.

137. MEUWISSEN R.L.J., OFFENBERG H.H., DIETRICH A.J.J., RIESEWIJK A., VAN IERSEL M., HEYTING C. A coiled-coil related protein specific for synapsed regions of meiotic prophase chromosomes. EMBO J., 1992, $11: 5091-5100$.

138. MIGNON A., ROUQUET N., JOULIN V. Les caspases, les protéases à cystéine de l'apoptose : un enjeu thérapeutique pour demain ? Med. Sci, 1998, $14: 9$.

139. MOENS P.B. Histones $\mathrm{H} 1$ and $\mathrm{H} 4$ of surfacespread meiotic chromosomes. Chromosoma, 1995, $104: 169-174$.

140. MORALES C.R., HAKE L.E., HECHT N.B. Cellular localization of the mRNAs of the somatic and testis-specific cytochromes $\mathrm{c}$ during spermatogenesis in the rat. Mol. Reprod. Dev., 1993, 34 : 196-205.

141. MORALES C.R., KWON Y.K., HECHT N.B. Cytoplasmic localization during storage and translation of the mRNAs of transition protein 1 and protamine 1 , two translationally regulated transcripts of the mammalian testis. J. Cell Sci., 1991, $100: 119-131$.

142. MORI C., WELCH J.E., FULCHER K.D., O'BRIEN D.A., EDDY E.M. Unique hexokinase messenger ribonucleic acids lacking the poring binding domain are developmentally expressed in mouse spermatogenetic cells. Biol. Reprod., 1993, 49 : 191-203.

143. MORITA T., YOSHIMURA Y., YAMAMOTO A. et al. A mouse homolog of the Escherichia coli recA and Saccharomyces cerevisiae RAD51 genes. Proc. Natl. Acad. Sci. USA, 1993, $90: 6577-6580$.

144. NAJMABADI H., HUANG V., YEN P. Substantial prevalence of microdeletions of the Y-chromosome in infertile men with idiopathic azoospermia and oligozoospermia detected using a sequence-tagged site-based mapping strategy. J. Clin. Endocrinol. Metab., 1996, $81: 1347-52$.

145. NAKAHORI Y., KUROKI Y., KOMAKI R. et al. The Y chromosome region essential for spermatogenesis. Horm. Res., 1996, $46: 20-23$.

146. NANTEL F., MONACO L., FOULKES N.S. et al. Spermiogenesis deficiency and germ-cell apoptosis in CREM-mutant mice. Nature, 1996, $380: 159$ 162. 
147. NAYERNIA K., BURKHARDT E., BEIMESCHE S., KEIME S., ENGEL W. Germ cell specific expression of a pro-acrosin-CAT fusion gene in transgenic mouse testis. Mol. Reprod. Dev., 1992, $31: 241-248$.

148. NAYERNIA K., REIM K., OBERWINKLER H., ENGEL W. Diploid expression and translational regulation of rat acrosin gene. Biochem. Biophys. Res. Commun., 1994, $202: 88-93$.

149. NICHOLSON D.W., ALI A., THORNBERRY N.A., VAILLANCOURT J.P. et al. Identification and inhibition of the ICE/CED-3 protease necessary for mammalian apoptosis. Nature, 1995, $376: 37-43$.

150. NOWAK R., SIEDLECKI J.A., KACZMAREK L., ZMUDZKA B.Z., WILSON S.H. Levels and size complexity of DNA polymerase $b$ mRNA in regenerating liver and other organs. Biochim. Biophys. Acta, 1989, $1008:$ 203-207.

151. NUNEZ G., BENEDICT M.A., HU Y., INOHARA N. Caspases : the proteases of the apoptotic pathway. Oncogene, 1998, $17: 3237-3245$.

152. OGURA T., TAKENOUCHI N., YAMAGUCHI M., MATSUKAGE A., SUGIMURA T., ESUMI $H$. Striking similarity of the distribution patterns of the poly[ADP-ribose] polymerase and DNA polymerase beta among various mouse organs. Biochem. Biophys. Res. Cpmmun., 1990, 172 : 377-384.

153. OYEN O., MYKLBUST F., SCOTT J.D. et al. Subunits of cyclic adenosine 3', 5' monophosphatedependant protein kinase show differential and distinct expression patterns during germ cell differenciation : alternative polyadenylation in germ cells gives rise tounique smaller-sized mRNA species. Biol. Reprod., 1990, $43:$ 46-54.

154. PACKER A.I., BESMER P., BACHAROVA R.F. Kit ligand mediates survival of type A-spermatogonia and dividing spermatocytes in postnatal mouse testes. Mol. Reprod. Dev., 1995, 42 : 303-310.

155. PENTIKAÏNEN V., ERKKILÄ K., DUNKEL L. Fas regulates germ cell apoptosis in the human testis in vitro. Am. J. Physiol., 1999, 276 : E310-E316.

156. PERI A., KRAUSZ C., CIOPPI F. et al. Cyclic adenosine 5'-monophosphate-responsive element modulator gene expression in germ cells of normoand oligospermic men. J. Clin. Endocrinol. Metab., 1998, 83 [10] : 3722-3726.

157. PERSENGIEV S.P., ROBERT S., KILPATRICK D.L. Transcription of the TATA binding protein gene is highly up-regulated during spermatogenesis. Mol. Endocrinol., 1996, 10 : 742-747.

158. PESCE M., WANG X., WOLGEMUTH D.J., SCHOLER H. Differential expression of the Oct-4 transcription factor during mouse germ cell differenciation. Mech. Dev., 1998, 71 : 89-98.

159. PRIGENT Y., MÜLLER S., DADOUNE J.P. Immunoelectron microscopical distribution of histones $\mathrm{H} 2 \mathrm{~B}$ and $\mathrm{H} 3$ and protamines during human spermiogenesis. Mol. Hum. Reprod., 1996, 2 : 929935.
160. QURESHI S.J., ROSS A.R., MA K. et al. Polymerase chain reaction sceening for $\mathrm{Y}$ chromosome microdeletions : a first step towards yhe diagnosis of genetically determined spermatogenesis failure in men. Mol. Hum ; Reprod., 1996, 2 : 775779 .

161. RAFF M.C. Social controls on cell survival and cell death. Nature, 1992, $356: 397-400$.

162. RAO M.R.S., RAO B.J., GANGULY J. Localization of testis-variant histones in rat testis chromatin. Biochem. J., 1982, 205 : 15-21.

163. RAO B.J., BRAHMACHARI S.K., RAO M.R.S. Structural organization of the meiotic prophase chromatin in the rat testis. J. Biol. Chem., 1983, $258: 13478-13485$.

164. RAO B.J., RAO M.R.S. Dnase I site mapping and micrococcal nuclease digestion of pachytene chromatin reveal novel structural features. J. Biol. Chem., 1987, 262 : 4472-4476.

165. REIJO R., LEE T., SALO P., et al. Diverse spermatogenic defects in humans caused by $\mathrm{Y}$ chromosome deletions encompassing a novel RNA-binding protein gene. Nat. Genet., 1995, $10: 383-393$.

166. REIJO R., ALAGAPPAN R.K., PATRIZIO P., PAGE D.C. Severe oligospermia resulting from deletions of azoospermia factor gene on Y-chromosome. Lancet, 1996, 347 : 1290-1293.

167. RICHTER J.D., Translational control during early development. Bioessays, 1991, 13 : 179-183.

168. ROBINSON M.O., MAC CARREY J.R., SIMON M.I. Transcriptional regulatory regions of testisspecific PGK2 defined in transgenic mice. Proc. Natl. Acad. Sci. USA, 1989, 86 : 8437-8441.

169. RODRIGUEZ I., ODY C., ARAKI K., GARCIA I., VASSALLI P. An early and massive wave of germinal cell apoptosis is required for the development of functional spermatogenesis. EMBO J., 1997, 16 [9]: 2262-2270.

170. ROSARIO M.O., PERKINS S.L., O'BRIEN D.A., ALLEN R.L., EDDY E.M. Identification of the gene for the developmentally expressed $70 \mathrm{kDa}$ heatshock protein [P70] of mouse spermatogenic cells. Dev. Biol., 1992, 150 : 1-11.

171. ROSS A.J., WAYMIRE K.G., MOSS J.E. Testicular degeneration in Bcl-w-deficient mice. Nat. Genet., 1998, $18:$ :251-256.

172. ROSSI P., DOLCI S., ALBANESI C., GRIMALDI P., RICCA R. Follicle-stimulating hormone induction of steel factor [SLF] mRNA in mouse Sertoli cells and stimulation of DNA synthesis in spermatogonia by soluble SLF. Dev. Biol., 1993, 155 : 68-74.

173. ROTTER V., SCHWARTZ D., ALMON E. et al. Mice with reduced levels of p53 protein exhibit the testicular giant-cell degenerative syndrom. Proc. Natl. Acad. Sci. USA, 1993, 90 : 9075-9079.

174. ROUX C., MATHIESON J., DADOUNE J.P. Immunocytological distribution of HP1 group protamines in human testes and ejaculated spermatozoa. Bull. Assoc. Anat., 1987 ; 71 : 65-69. 
175. ROUX C., GUSSE M., CHEVAILLIER P., DADOUNE J.P. An antiserum against protamines for immunochemical studies of histone to protamine transition during human spermiogenesis. J. Reprod. Fertil., $1988 ; 82: 35-42$.

176. RUGGIU M., COOKE H. Y bind RNA for spermatogenesis. Int. J. Androl., 1999, 22 : 19-27.

177. SAUNDERS P.T.K., GAUGHAN J., SAXTY B.A., KERR L.E., MILLAR M.R. Expression of protamine P2 in the testis of the common marmoset and man visualized using non-radioactive in-situ hybridization. Int. J. Androl., 1996, 19 : 212-219 .

178. SAXENA R., BROWN L.G., HAWKINS T., et al. The DAZ gene cluster on the human Y chromosome arose from an autosomal gene that was transposed, repeatedly amplifies and pruned. Nat. Genet., 1996, $14: 292-298$.

179. SCHMEKEL K., MEUWISSEN R.L.J., DIETRICH A.J.J. et al. Organization of SCP1 protein molecules within synaptonemal complexes of the rat. Exp. Cell Res., 1996, $226: 20-30$

180. SCHMIDT E.E., SCHNIBLER U. Developmental testis-specific regulation of mRNA levels and mRNA translational efficiencies for TATA-binding protein mRNA isoforms. Dev. Biol., 1997, 184 : 138149.

181. SCHOLER H.R., HATZOPOULOS A.K., BALLING R., SUZUKI N., GRUSS P. A family of octamer-specific proteins present during mouse embryogenesis : evidence for germline-specific expression of an Oct-factor. EMBO J. 1989, $8:$ 2543-2550.

182. SCHWARTZ D., GOLDFINGER N., ROTTER V. Expression of p53 protein in spermatogenesis is confined to the tetraploid pachytene primary spermatocytes. Oncogene, 1993, $8: 1487-1494$.

183. SCULLY R., CHEN J., PLUG A. et al. Association of BRCA1 with RAD51 in mitotic and meiotic cells. Cell , 1996, 88 : 265-275.

184. SHARPE R.M. : Regulation of spermatogenesis. In Knobil E, Neill J.D., eds. Physiology of reproduction, 1994, 2nd ed. New York : Raven Press ; 13631434.

185. SHINOHARA A., OGAWA H., MATSUDA Y., USHIO N., IKEO K., OGAWA T. Cloning of human, mouse and fission yeast recombination genes homologous to RAD51 and recA. Nature Genet., 1993, $4: 239-243$.

186. SIMBULAN-ROSENTHAL C.M., ROSENTHAL D.S., HILZ H. et al. The expression of poly[ADPribose] polymerase during differenciation-linked DNA replication reveals that it is a component of the multiprotein DNA replication complex. Biochemistry, 1996, 35 : 11622-11633.

187. SINGER-SAM J., ROBINSON M.O., BELLVE A.R., SIMON M.I., RIGGS A.D. Measurement by quantitative PCR of changes in HPRT, PGK 1, PGK2, APRT, Mtase and Zfy gene transcripts during mouse spermatogenesis. Nucleic Acids Res., $1990,18: 1255-1259$.
188. SJOBLOM T., LAHDETIE J. Expression of p53 in normal and $\mathrm{X}$-irradiated rat testis suggests a role for p53 in meiotic recombination and repair. Oncogene, 1996, $12:$ 2499-2505.

189. SOLARY E. L'apoptose : mécanismes moléculaires. C.R. Soc. Biol. , 1998, 192 : 1065-1076.

190. STEGER K., KLONISCH T., GAVENIS K., DRABENT B., DOENECKE D., BERGMANN $M$. Expression of $\mathrm{mRNA}$ and protein of nucleoproteins during human spermiogenesis. Mol. Hum. Reprod., 1998, $4: 939-945$.

191. STELLER H. Mechanisms and genes of cellular suicide. Science, 1995, $267: 1445-1449$.

192. SUN Z., SASSONE-CORSI P., MEANS A. Calspermin gene transcription is regulated by two cyclic AMP response elements contained in an alternative promoter in the calmodulin kinase IV gene. Mol. Cell. Biol., 1995, $15: 561-571$.

193. TAJIMA Y., ONOUE H., KITAMURA Y., NISHIMUNE Y. Biologically active kit ligand growth factor is produced by mouse Sertoli cells and is defective in Sld mutant mice. Development, 1991, 113 : 1031-1035.

194. THOMAS K., DEL MASO J., EVERSOLE P. et al. Developmental regulation of expression of the lactate deshydrogenase $[\mathrm{LDH}]$ multigene family during mouse spermatogenesis. Development , 1990, $109: 483-493$.

195. THOMPSON C.B. Apoptosis in the pathogenesis and treatment of disease. Science, 1995, $267: 1456-$ 1462.

196. TOSCANI A., METTUS R.V., COUPLAND R. et al. Arrest of spermatogenesis and defective breast development in mice lacking A-myb. Nature, 1997, $386: 713-717$.

197. TSUNEKAWA N., MATSUMOTO M., TONE S., NISHIDA T., FUJIMOTO H. The Hsp70 homolog gene, Hsc70t, is expressed under translational control during mouse spermiogenesis. Mol. Reprod. Dev., 1999, 52 [4] : 383-391.

198. VANDEBERG J.L. The phosphoglycerate kinase isoenzyme system in mammals : biochemical, genetic, developmental and evolutionnary aspects. Isoenzymes Curr. Top. Biol. Med. Res., 1985, 12 : 133-187.

199. VANDEBERG J.L., COWPER D.W., CLOSE P.J. Mammalian testis phosphoglycerate kinase. J. Exp. Zool., 1976, 198 : 231-239.

200. VAUX D.L., HAECKER G., STRASSER A. An evolutionary perspective on apoptosis. Cell, 1994, 76 : 777-779.

201. VINCENT S., SEGRETAIN D., NISHIKAWA S. et al. Stage-specific expression of the kit receptor and its ligand during male gametogenesis in the mouse: a kit-KL interaction critical for meiosis. Development, 1998, 125 : 4585-4593.

202. VIRBASIUS J.V., SCARPULLA R.C. Structure and expression of rodent genes encoding the testis-specific cytochrome $c$ : differences in gene structure 
and evolution between somatic and testicular variants. J. Biol. Chem., 1988, 263 : 6791-6796.

203. VOLIVA C.F., MARTIN S.A, HUTCHINSON C.A., EDGELL M.H. Dispersal process associated with the L1 family of interspersed repetitive DNA sequences. J. Mol. Biol., 1984, 178 : 795-813.

204. WALKER H.W., HABENER J.F. Role of transcription factors CREB and CREM in cAMP-regulated transcription during spermatogenesis. Trends Endocrinol., 1996, 7 : 133-138.

205. WALPITA D., PLUG A.W., NEFF N.F., GERMAN J., ASHLEY T. Bloom's syndrome protein, BLM, colocalizes with replication protein A in meiotic prophase nuclei of mammalian spermatocytes. Proc. Natl. Acad. Sci. USA, 1999, 96 [10] : 56225627.

206. WALTER C.A., TROLIAN D.A., MAC FARLAND M.B., STREET K.A., GURAN G.R., MAC CARREY J.R. Xrcc-1 expression during male meiosis in the mouse. Biol. Reprod.,1996, 55 : 630-635.

207. WANG Z.Q., AUER B., STINGL. L. et al. Mice lacking ADPRT and poly[ADP-ribosyl]ation develop normally but are susceptible to skin disease. Genes Dev., 1995, 9 : 509-520.

208. WANG Z., KIM K.H. Vitamin A-deficient testis germ cells are arrested at the end of $\mathrm{S}$ phase of the cell cycle : a molecular study of the origin of synchonous spermatogenesis in regenerated seminiferous tubules. Biol. Reprod., 1993, 48 : 1157-1165.

209. WEINBAUER G.F., BEHR R., BERGMANN M., NIESCHLAG E. Testicular cAMP responsive element modulator [CREM] protein is expressed in round spermatids but is absent or reduced in men with round spermatid maturation arrest. Mol. Hum. Reprod., 1998, 4 : 9-15.

210. WELCH J.E., O'RAND M.G. Characterization of a sperm-specific nuclear autoantigenic protein. Expression and localization in the testis. Biol. Reprod., 1990, 43, 569-578.

211. WHITE E. Life, death and the pursuit of apoptosis. Genes Dev., 1996, 10 : 1-15.

212. WITTE O.N., Steel locus defines new multipotent growth factor. Cell, 1990, 63:5-6.

213. WOLFE S.A., ANDERSON J.V., GRIMES S.R., STEIN G.S., STEIN J.S. Comparison of the structural organization and expression of germinal and somatic rat histone $\mathrm{H} 4$ genes. Biochem. Biophys. Acta., 1989, 1007 : 140-145.

214. WOLFE S.A., GRIMES S.R. Protein-DNA interactions within the rat histone $\mathrm{H} 4 \mathrm{t}$ promoter. J. Biol. Chem. 1991, $266:$ 6637-6643.

215. WOLFE S.A., GRIMES S.R. Histone H1t : a tissuespecific model used to study transcriptional control and nuclear function during cellular differenciation. J. Cell. Biochem., 1993, 53 : 156-160.

216. WOLFE H., KOGAWA K., MILLETTE C.F., COOPER G.M. Specific expression of nuclear proto-oncogenes before entry into meiotic prophase of spermatogenesis. Science, 1989, $245: 740-743$.
217. WOLGEMUTH D.J., VIVIANO C.M., GIZANGGINSBERG E., FROHMAN M.A., JOYNER A.L., MARTIN G.R. Differential expression of the mouse homeobox containing gene Hox-1,4 during male germ cell differenciation and embryonic development. Proc. Natl. Acad. Sci. USA, 1987, 84 : 58135817.

218. WORMINGTON M. Poly[A] and translation : developmental control. Curr. Opin. Cell. Biol., 1993, 5 : 950-954.

219. WU S., WOLGEMUTH D.J. The distinct and developmentally regulated patterns of expression of members of the mouse cdc 25 gene family suggest differential function during gametogenesis. Dev. Biol., 1995, 170 : 195-206.

220. WYKES S.M., NELSON J.E., VISSCHER D.W., DJAKIEW D., KRAWETZ S.A. Coordinate expression of the PRM1, PRM2 and TNP2 multigene locus in human testis. DNA Cell Biol.,1995, 14 : 155-161.

221. WYKES S.M., VISSCHER D.W., KRAWETZ S.A. Haploid transcripts persist in mature human spermatozoa. Mol. Hum. Reprod., 1997, 3 : 15-19.

222. XU Y., ASHLEY T., BRAINERD E.E., BRONSON R.T., MEYN M.S., BALTIMORE D. Targeted disruption of ATM leads to growth retardation, chromosomal fragmentation during meiosis, immune defects and thymic lymphoma. Genes Dev., 1996, $10: 2411-2422$.

223. YELICK P.C., KWON Y.H., FLYNN J.F., BORZORGZADEH A., KLEENE J.C., HECHT N.B. Mouse transition protein 1 is translationally regulated the postmeiotic stages of spermatogenesis. Mol. Reprod. Dev., 1989, 1 : 193-200.

224. YEN P.H., CHAI N.N., SALIDO E.C. The human DAZ genes, a putative male infertility factor on the $\mathrm{Y}$ chromosome, are highly polymorphic in the DAZ repeat regions. Mamm. Genom., 1997, 8 : 756-759.

225. YEN P.H., CHAI N.N., SALIDO E.C. The human autosomal gene DAZLA : testis specificity and a candidate for male infertility. Hum. Mol. Genet., 1996, 5 : 2013-2017.

226. YIN Y., STAHL B.C., DEWOLF W.C., MORGENTALER A. p53-mediated germ cell quality control in spermatogenesis. Dev. Biol., 1998, 204 : 165-171.

227. YOMOGIDA K., OHTANI H., HARIGAE H. et al. Developmental stage-and spermatogenic cycle-specific expression of transcription factor GATA-1 in mouse Sertoli cells. Development, 1994, 120 : 1759-66.

228. YOSHINAGA K., NISHIKAWA S., OGAWA M., HAYASHI S.I. Role of c-kit in mouse spermatogenesis : identification of spermatogonia as a specific site of c-kit expression and function. Development, 1991, $113: 689-699$.

229. ZABLUDOFF S.D., WRIGHT W.W., HARSHMAN $\mathrm{K}$., WOLD B.J. BRCA1 mRNA is expressed highly during meiosis and spermiogenesis but not during mitosis in male germ cells. Oncogene, 1996, 13 : 649-653. 
230. ZAKERI Z.F., WOLGEMUTH D.J., HUNT C.R. Identification and sequence analysis of a new member of the mouse HSP70 family and characterization of its unique cellular and developmental pattern of expression in the male germ line. Mol. Cell. Biol., 1988, 8 : 2925-2932.

231. ZHANG X., LEHMANN J., HOFFMANN B. et al. Homodimer formation of retinoid $X$ receptor induced by 9 -cis retinoic acid. Nature, 1992, 358 : 587591.

232. ZHANG L.P., STROUD J., EDDY C.A., WALTER C.A., MAC CARREY J.R. Multiple elements influence transcriptional regulation from the human testis-specific PGK2 promoter in transgenic mice. Biol. Reprod., 1999, 60 [6] : 1329-1337.

233. ZHOU Y., SUN Z., MEANS A.R., SASSONECORSI P., BERNSTEIN K.E. cAMP- response element modulator $t$ is a positive regulator of testis angiotensin converting enzyme transcription. Proc. Natl. Sci. USA, 1996, 93 : 12262-12266.

234. ZHU D., DIX D.J., EDDY E.M. HSP70-2 is required for CDC2 kinase activity in meiosis I of mouse spermatocytes. Development, $1997 ; 124$ [15] : 3007-3014.

\author{
ABSTRACT \\ Gene expression during spermatogenesis and \\ their regulation

\section{DROUINEAUD, C. JIMENEZ}

Sperm production results from a coordinated and complex process of cell division and differenciation named spermatogenesis. Each stage of this process, spermatogonial division and differenciation, meiosis and spermiogenesis is under the control of a wide variety of genes, differentially expressed in the testis.

Spermatogonial multiplication is regulated by the c-kit/SCF system while the balance between pro- and anti-apoptotic genes expression allows the limitation of the number of these cells. Mammalian meiosis is regulated by many gene families. These include genes of : structural proteins of the nucleus (lamins, histones, synaptonemal complex components) ; enzymes of energy metabolism (pgk2, hk1-sa, -sb, -sc, pgam2, ldh3, pdha2, cyt ct and cs) ; proteins acting in DNA repair and meiotic recombination ( $r a d ~ 51$, pms2, mlh1...) ; cell cycle (cyclin/CDC2 complex, tumor-suppressor proteins, HSP-70 protein) ; c-kit/SCF sys- tem. Spermiogenesis, the late stage of spermatogenesis is characterized by a dramatic remodelling of chromatin, which involves morphological changes and a highly regulated expression of the nuclear basic proteins : in round spermatids, both histones and non histone proteins are replaced by transition proteins and are eliminated from the cell. In elongating spermatids, transition proteins are removed from the condensing chromatin and are replaced by protamins.

Two categories of genes can be distinguished among those expressed during spermatogenesis :

genes expressed exclusively in spermatogenic cells ;

genes expressed in somatic cells but coding for testis-specific iso-enzyme (enzymes of energy metabolism...)

In fact, the expression of genes during spermatogenesis is subject to transcriptional, post-transcriptional and translational regulation. The transcriptional control is mainly provided by transcription factors, which are neither specific of the germ cells or common but differentially expressed in germ cells. The genes coding for these transcription factors are themselves regulated. The choice of a specific promoter is another regulatory mechanism of some genes transcribed in the testis (CREM and CREB, cyt cs). The post-transcriptional regulation consits in an alternative splicing of some genes expressed in somatic cells (lamins C2, B3, HK1-sa, -sb, sc). Finally, translational regulation of genes expressed in male germ cells is particularly important during spermiogenesis. The length of the polyA tail and the presence of the 3' and 5' untranslated regions of the ARNm are importants elements in this regulation.

Key-words : spermatogenesis, gene, regulation, transcription, translation, apoptosis. 